\title{
Stay or leave? The effects of communicative infidelity on relationship outcomes
}

\author{
Colleen C. Malachowski \\ West Virginia University
}

Follow this and additional works at: https://researchrepository.wvu.edu/etd

\section{Recommended Citation}

Malachowski, Colleen C., "Stay or leave? The effects of communicative infidelity on relationship outcomes" (2009). Graduate Theses, Dissertations, and Problem Reports. 794.

https://researchrepository.wvu.edu/etd/794

This Thesis is protected by copyright and/or related rights. It has been brought to you by the The Research Repository @ WVU with permission from the rights-holder(s). You are free to use this Thesis in any way that is permitted by the copyright and related rights legislation that applies to your use. For other uses you must obtain permission from the rights-holder(s) directly, unless additional rights are indicated by a Creative Commons license in the record and/ or on the work itself. This Thesis has been accepted for inclusion in WVU Graduate Theses, Dissertations, and Problem Reports collection by an authorized administrator of The Research Repository @ WVU. For more information, please contact researchrepository@mail.wvu.edu. 
Stay or Leave? The Effects of Communicative Infidelity on Relationship Outcomes

\title{
Colleen C. Malachowski
}

\author{
Thesis submitted to the \\ Eberly College of Arts and Sciences \\ at West Virginia University \\ in partial fulfillment of the requirements \\ for the degree of \\ Master of Arts \\ in \\ Communication Theory and Research
}
Megan R. Dillow, Ph.D., Chair
Maria Brann, Ph.D.
Keith Weber, Ed.D.

Department of Communication Studies

Morgantown, West Virginia
2009

Keywords: Communicative Infidelity; Investment Model; Forgiveness; Exit; Voice; Neglect 


\section{ABSTRACT \\ Stay or Leave? The Effects of Communicative Infidelity on Relationship Outcomes}

\section{Colleen C. Malachowski}

The purpose of this study was to examine the effects of communicative infidelity (CI) motives on relationship outcomes. CI motives include jealousy, vengefulness, sexual selfesteem, sexual depression, and sexual preoccupation, while outcomes included forgiveness, reparation, voice, exit, loyalty, and neglect responses. Additionally, this study tested the relationship of commitment and satisfaction to relational outcomes. Participants were 215 undergraduate students currently involved in a romantic relationship. Participants were instructed to answer questions measuring their commitment and satisfaction levels, as well as read and respond to a CI scenario. Results indicated that commitment is positively related to voice responses and negatively related to neglect responses, while satisfaction is negatively related to neglect responses. Results also revealed that commitment and satisfaction are negatively related to forgiveness by minimizing. Additionally, significant differences were found in the ways that men and women respond following the discovery of a partner's transgression. Specifically, men reported reacting to the discovery of a partner's CI with more exit and neglect responses and less voice responses than women. Finally, both sexes rated all CI motives as relatively unacceptable. 


\section{ACKNOWLEDGEMENTS}

Dr. Dillow: Thank you for the time and energy you put into assisting me with this project. Without your support and guidance, I would have never made it this far. You have taught me so much in a short period of time and I will be forever grateful.

Dr. Brann: Thank you for your suggestions, comments, and revisions throughout this process. Your guidance and expertise helped to make this project the best that it could be.

Dr. Weber: Thank you for your encouragement and assistance throughout this study. Your expertise in research methods really contributed to this study. Thanks for always pushing me to do the best I can.

Dr. Martin: Thank you for your assistance in helping us to construct the scenarios used in this study. Your guidance was greatly appreciated.

Dr. Spitzberg: Thank you for providing us with your data on communicative infidelity. Your assistance was appreciated. 


\section{TABLE OF CONTENTS}

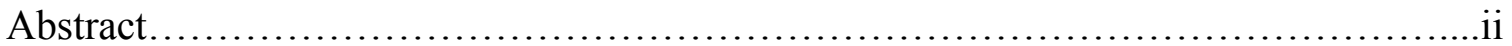

Acknowledgements.............................................................

Table of Contents.............................................................

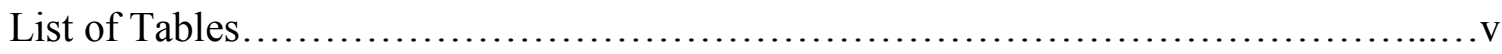

Chapter 1 - Literature Review................................................

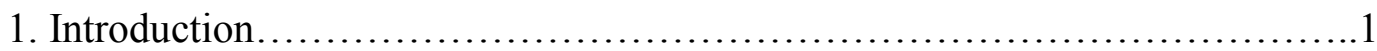

2. Relational Transgressions...........................................2

3. The Investment Model...............................................6

4. Rationale....................................................... 9

5. Communicative Infidelity...........................................

6. Communicative Infidelity Motives.................................11

7. Relationship Outcomes...........................................14

Chapter 2 - Method.........................................................23

1. Participants......................................................26

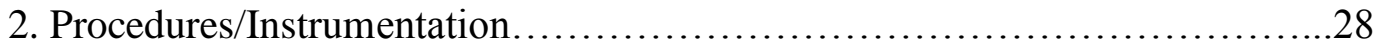

3. Measures........................................................ 28

Chapter 3 - Results.................................................... 34

Chapter 4 - Discussion.................................................. 39

References............................................................49

Appendices...............................................................56

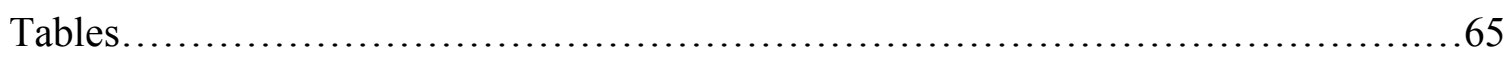

Curriculum Vitae......................................................... 72 


\section{LIST OF TABLES}

Table 1 Correlations among Pre-Transgression Commitment and Satisfaction, and Post-Transgression Loyalty, Voice, Forgiveness, and Reparation Responses.

Table 2 Multivariate Analysis of Variance Assessing the Relationships among CI Motives and Relational Responses

Table 3 Hierarchical Regression Testing the Moderating Impact of CI Motive on the Relationship between Pre-Transgression Commitment and Post-Transgression Voice Responses...

Table 4 Hierarchical Regression Testing the Moderating Impact of CI Motive on the Relationship between Pre-Transgression Commitment and Post-Transgression Neglect Reponses....

Table 5 Hierarchical Regression Testing the Moderating Impact of CI Motive on the Relationship between Pre-Transgression Satisfaction and Post-Transgression Neglect Responses

Table 6 Hierarchical Regression Testing the Moderating Impact of CI Motive on the Relationship between Pre-Transgression Commitment and Post-Transgression Forgiveness by Minimizing Responses.

Table 7 Hierarchical Regression Testing the Moderating Impact of CI Motive on the Relationship between Pre-Transgression Satisfaction and Post-Transgression Forgiveness by Minimizing Responses. 


\section{CHAPTER ONE}

Introduction

Even the strongest romantic relationships can be compromised when one partner commits a hurtful act or violates the established trust of a relationship - or in other words, commits a relational transgression. A relational transgression is a violation of the implicit or explicit norms and rules of a relationship (Metts \& Cupach, 2007). Essentially, a transgression is a breach of relationship expectations and usually stimulates feelings of betrayal, doubt, and uncertainty for the person who was transgressed against.

Transgressions can vary from simple bothersome behaviors, such as nagging or being disrespectful, to severe violations like infidelity or breaking promises, which threaten the well-being of a relationship (Jones, Moore, Schratter, \& Negel, 2001).

Infidelity as a relational transgression has been explored in the communication field, and is commonly defined as an emotional or sexual engagement with a third party that violates the norms of relational exclusivity (Boekhout, Hendrick, \& Hendrick, 2003; Tafoya \& Spitzberg, 2007). Infidelity has been identified as one of the most severe types of relational transgressions, and recent research shows that $30 \%$ to $40 \%$ of relationships are tainted by a least one incident of sexual infidelity (Guerrero \& Bachman, 2008). Furthermore, Jones et al. (2001) note that $50 \%$ of all marriages experience infidelity, and it is a transgression that occurs cross-culturally in all classes, races, and religions.

Despite the plethora of extant empirical research, some facets of infidelity remain unexplored. One such facet is communicative infidelity, a new and understudied topic in the communication field. Understanding the underlying messages that are communicated to a partner through infidelity can shed light on the myriad of ways that infidelity may 
affect a relationship. Additionally, studying the motives that trigger the commission of infidelity can offer insight into the state of a relationship before infidelity is committed and how that state can affect the outcomes of a relationship. The purpose of this study is to examine how infidelity works communicatively and to explore how the motives behind this specific type of infidelity affect relational outcomes. Using the investment model as a guiding framework, transgression and infidelity literature will be reviewed, with particular consideration given to the motives behind infidelity. First, a review of relational transgressions will be provided.

\section{Review of Literature}

\section{Reactions to Relational Transgressions}

Although relational transgressions have the ability to affect relationships in several different ways, scholars have found compelling evidence to suggest that individuals sometimes choose to respond pro-socially to transgressions, resulting in forgiveness or reparation outcomes (Brandau-Brown \& Ragsdale, 2008; Dindia \& Baxter, 1987; Dunleavy, Goodboy, Booth-Butterfield, Sidelinger, \& Banfield, 2007; EmmersSommer, 2003; Finkel, Rusbult, Kumashiro, \& Hannon, 2002; Kachadourian, Fincham, \& Davila, 2004; Roloff, Soule, \& Carey, 2001; Stafford, Dainton, \& Haas, 2000). Often, however, these outcomes depend on the presence of certain qualities in the relationship prior to the transgression, such as satisfaction and commitment.

According to Fincham (2000), forgiveness is a construct that manifests in affect, cognition, and outward behaviors. Forgiveness is an intentional, unconditional, and supererogatory process that is distinct from repair (Fincham). Repair "implies that something has gone awry that needs correcting" (Dindia \& Baxter, 1987, p. 144). Repair 
differs from forgiveness in that it involves physical and mental efforts to restore the relationship, whereas forgiveness is when one partner attempts to let go of negative feelings toward the other partner (Kachadourian et al., 2004).

In a study conducted by Dindia and Baxter (1987), pro-social strategies such as refraining from criticism, being cheerful, and openness were identified as successful repair strategies used most often in marital relationships. More recently, Brandau-Brown and Ragsdale (2008) examined relational repair in marital relationships. After surveying 239 married couples, assurances, openness, and time were identified as three repair strategies used most often in marriages. Assurances refer to the statements used to reassure a partner of the relationship's well-being and future, openness is associated with self-disclosure, and time refers to the time spent with a spouse. While time spent with a spouse increases relationship investment, assurances contribute to relational satisfaction. Both time and assurances increase overall commitment to a relationship, suggesting that commitment is associated with repair strategies.

Brandau-Brown and Ragsdale (2008) then tested the relationships among personal, moral, and structural commitment and repair strategies. Personal commitment refers to the individual's desire to stay in the relationship, structural commitment is associated with the external constraints of the relationship (e.g., children, housing, potential relational alternatives), and moral commitment refers to the feelings of obligation to stay in the relationship. Findings from this study revealed positive relationships between personal (e.g., "I want to stay in this relationship") and structural (e.g., "I have to stay in this relationship") commitment and all four relational repair strategies (Brandau-Brown \& Ragsdale). Furthermore, moral (e.g., "I ought to stay in this 
relationship") commitment was found to be significantly related to assurances, openness, and time. These results suggest that various aspects of commitment play a significant role in the likelihood of using relational repair strategies.

Other significant findings with regard to relational repair were revealed in a study conducted by Dunleavy et al. (2007). In examining how marital couples repair relationships in response to hurtful messages, it was found that silence is the least effective repair strategy, and repair strategies are not influenced by the intention or purposefulness of a hurtful message. Additionally, results from Emmers and Canary (1996) revealed that interactive communication behaviors, such as relationship talk, listening, comforting, supporting, and having sex with the partner, were the most effective behaviors in achieving relational repair in dating relationships. Furthermore, males' passive strategies, such as taking time away from a partner, were associated with males' own beliefs that the relationship was repaired. Conversely, females' active strategies, such as giving gifts and initiating dates, were positively related to self-report and partner-attributed beliefs that the relationship was repaired. Active and interactive strategies (e.g., talking, spending more time together) are all attempts to increase relationship satisfaction and investment, which could, in turn, increase overall relationship commitment. Therefore, repair seems to be driven, at least in part, by a desire for increased satisfaction and commitment.

In addition to repair, much of the current literature on transgressions is rooted in the research on forgiveness. Allemand et al. (2007) examined the association between satisfaction and forgiveness in romantic relationships after a transgression is committed. Results from this investigation of individuals in romantic relationships revealed that 
relationship satisfaction moderated the link between trait forgiveness (i.e., a person's general tendency to be more or less forgiving across a variety of different situations) and episodic forgiveness (i.e., forgiveness after a specific event, such as a relational transgression). Relationship satisfaction was positively related to trait and episodic forgiveness, such that highly satisfied individuals were more likely to forgive in both circumstances. These findings are consistent with past research regarding forgiveness, in which relationship satisfaction was positively associated with forgiveness after a transgression (Fincham, 2000; Gordon \& Baucom, 2003; Kachadourian et al., 2004).

In addition, Finkel et al. (2002) found that commitment was considered to be a pro-relationship motivation that prompted intent to persist and forgive. Furthermore, the findings by Finkel et al. indicated that the relationship between commitment and forgiveness was mediated by the cognitive interpretation of a transgression, suggesting that perceptions of the motives behind a transgression can affect relational forgiveness. Along with commitment, relationship satisfaction and a positive self-image have also been found to increase the chance of relational forgiveness (Kachadourian et al., 2004). Additionally, McCullough et al. (1998) discovered that individuals with greater relationship satisfaction and commitment are more likely to forgive their partner after a transgression takes place. On the other hand, forgiveness has been shown to impact relational characteristics such as commitment. Tsang, McCullough, and Fincham (2006) found that forgiveness increased relationship closeness and commitment after the occurrence of a transgression in a romantic relationship.

As noted previously, research related to repair and forgiveness suggests that the qualities of a relationship that are present before a transgression occurs will influence 
partners' responses following the transgression. Two such characteristics that have been shown to impact subsequent relational decisions and behaviors are satisfaction and commitment, both key components of the investment model. As such, we turn to the investment model as a useful guide for explaining why individuals may engage in prosocial responses, such as forgiveness and reparation, to partner-committed transgressions.

\section{Theoretical Framework: The Investment Model}

Rusbult's (1980, 1983) investment model provides a useful framework for understanding why some relational transgressions occur, and more importantly for the purposes of this study, how reactions to transgressions affect relationships. The investment model proposes that, in general, commitment is the best predictor in determining whether an individual chooses to remain in a relationship. According to the investment model, an individual's commitment level is influenced by his/her relationship satisfaction, perceived quality of alternatives, and investment size (Rusbult 1980, 1983). Commitment also mediates the probability of relationship persistence based on the satisfaction, alternatives, and investments of a relationship.

Rusbult $(1980,1983)$ conceptualizes satisfaction as the perceived rewards versus the perceived costs of a relationship. Rewards are the positive material or psychological attributes of a relationship, such as sexual satisfaction, comfort, or gifts. In contrast, costs are the negative material or psychological attributes of a relationship, such as time or money (Rusbult, 1980). Essentially, satisfaction is high when rewards outweigh the costs of a relationship; conversely, satisfaction is low when costs outweigh rewards.

Next, quality of alternatives refers to an individual's perception of his/her options outside of the relationship. These options may include being alone or dating other 
individuals. Typically, when perceived alternatives are high, commitment level decreases and vice versa. Finally, investments are the tangible and intangible relational inputs that would be lost if the relationship were to end (e.g., time, joint possessions, social networks). Individuals in relationships that carry high investments have also been found to be more committed (Rusbult 1980, 1983). Rusbult (1983) tested this model in a longitudinal study, and found that individuals' desire to stay together (i.e., commitment) was high when rewards outweighed costs, alternatives were low, and investments were high. These findings are consistent in many types of relationships including European and African American dating couples (Davis \& Strube, 1993), adult dating relationships (Rusbult, Johnson, \& Morrow, 1986), marital relationships (Rusbult, Bissonnette, Arriaga, \& Cox, 1998), and friendships (Lin \& Rusbult, 1995).

The investment model has been used as a framework for examining the occurrence of infidelity, as well as subsequent relational outcomes and partner responses to transgressions. For example, Drigotas, Safstrom, and Gentilia (1999) conducted a twopart longitudinal study with individuals involved in romantic relationships. In the first part of the study, commitment levels of undergraduates in relationships were assessed via a survey at the beginning of the semester (i.e., time one), which asked questions regarding satisfaction levels, investments, and quality of alternatives. A few months later, the same respondents were asked to keep a diary regarding their thoughts and actions toward individuals other than their relational partners while on spring break (i.e., time two). These diaries were then evaluated qualitatively using descriptive analysis to compare commitment levels on the survey portion of the study with commitment levels based on the interactions with third parties described in the diaries on spring break. It was 
found that individuals' commitment levels at time one successfully predicted the emotional and physical intimacy of participant interactions with third parties on spring break. Individuals with low commitment levels were found to have more intimate emotional and physical interactions with others outside of the relationship at time two. Drigotas et al. (1999) conclude, “....issues of satisfaction and alternative quality (and investment) affect infidelity by eroding commitment to the relationship...It is commitment that directly affects infidelity" (p. 510).

More importantly for the purposes of this study, communication scholars (and others) have turned to the investment model to investigate the aftermath of transgressions in relationships. For example, Guerrero and Bachman (2008) used the investment model to examine the communication that follows a relational transgression (i.e., infidelity). In phase one of their longitudinal study, a questionnaire was administered to undergraduates who were involved in ongoing romantic relationships. Satisfaction, investment, and quality of alternatives were all found to predict commitment. In phase two of their study, respondents who had experienced a relational transgression since completing the first phase of the study were asked to explain the communication they engaged in after the transgression took place. These scholars found that individuals involved in relationships with greater satisfaction, high investments, and low alternatives communicated more constructively and less destructively when their relationship was threatened. More specifically, constructive communication was used to repair the relationship, while destructive communication was used to terminate the relationship.

Additionally, a study conducted by Choice and Lamke (1990) revealed that relationship satisfaction, alternatives, and investments accounted for $87 \%$ of an 
individual's choice to continue or terminate an abusive dating relationship. Consistent with these findings, Rhatigan and Street (2005) found that violence negatively impacts relational satisfaction, decreases commitment, and is positively associated with decisions to leave the abusive relationship. Commitment has also been found to be positively correlated with decisions to leave a sexually coercive or abusive relationship (Katz, Kuffel, \& Brown, 2006; Rhatigan \& Axsom, 2006). Taken together, results from these studies suggest that constructs from the investment model can be fruitfully employed to make predictions regarding relationship outcomes after a transgression occurs.

\section{Rationale for the Study}

Based on the research conducted with the investment model, it is clear that commitment has a strong impact on relational outcomes after a transgression is committed, and the investment model can be used to explain individuals' responses to transgressions in relationships. Specifically, the investment model is helpful in making predictions regarding individuals' responses to a partner's physical infidelity. Recently, however, another form of infidelity (i.e., communicative infidelity) has been identified by communication scholars (Tafoya \& Spitzberg, 2007). As of yet, infidelity as a way to send a specific message to a partner in order to get a response that affects the relationship outcome has not been fully explored. The notion of infidelity as a two-way, dyadic process merits further study, as it can offer insight into how infidelity messages can positively or negatively affect relationships.

\section{Communicative Infidelity}

Recently, Tafoya and Spitzberg (2007) proposed an alternative approach by which to conceptualize infidelity. They suggested that infidelity be viewed as a 
communicative act, thus coining the term communicative infidelity $(\mathrm{CI})$. $\mathrm{CI}$ is defined as any extra dyadic sexual activity "intended in part to send a message to a former, current, or prospective romantic dyad partner" (Tafoya \& Spitzberg, p. 224). It is important to note that $\mathrm{CI}$ is concerned only with sexual extra dyadic activity, and not emotional affairs.

Tafoya and Spitzberg (2007) explain that CI may be a strategy to indirectly send a message to a partner. For example, CI may be used as a way to make a partner jealous, seek revenge, or gain attention. Essentially, CI is used specifically to send a message to another person, and presumably has certain motives behind it. In order to identify these specific motives, an exploratory pilot study was conducted by Spitzberg and Tafoya (2005) in which participants were asked to answer open-ended questions providing their reasons, justifications, and acceptability levels (i.e., whether they approve or disapprove of the motive) for engaging in infidelity. It was found that the most justifiable reasons for engaging in infidelity included relief of sexual frustration; desire for sexual excitement and pleasure; to obtain love, affection, and companionship; or when falling in love with another person. The pilot study also indicated that infidelity is perceived to be acceptable in some cases, such as relief of sexual frustration or when in love with another person, and that there are specific communicative motives for committing infidelity (i.e., jealousy, sociosexuality, and vengefulness).

In a follow-up investigation, Spitzberg and Tafoya (2005) hypothesized that jealousy, sociosexuality, and vengefulness motives would be positively related to the evaluation of $\mathrm{CI}$ as an acceptable behavior. However, although sociosexuality and vengeful motives were positively related to the acceptability and justification of CI, the 
jealousy motive was negatively related to the acceptability and justification of CI.

Furthermore, sex differences were found between males and females in their approval and justification of CI, with men considering CI more justifiable and acceptable in all cases than women. Consistent results were found by Spitzberg and Chou (2005), in which vengefulness successfully predicted strategic infidelity and infidelity justification.

The authors of these studies declare that additional empirical research on $\mathrm{CI}$ is needed in order to further understand the implications of infidelity specifically as a communicative act motivated by jealousy, sociosexuality, or vengefulness. If $\mathrm{CI}$ is a communicative act strategically intended to send a message, then the message that is sent should impact the current relationship in some manner. In this way, CI is likely to result in specific communicative and behavioral responses (e.g., reparation, forgiveness, continuation, or termination) after the CI messages are sent. Furthermore, these outcomes are not likely to be influenced solely by CI, but also by the state of the relationship before $\mathrm{CI}$ is committed. Based on the research presented previously, it is clear that there is a relationship between satisfaction, commitment, and relationship outcomes (Drigotas et al., 1999; Katz, Kuffel, \& Brown, 2006; Rhatigan \& Axsom, 2006). It is expected also that CI motives may moderate the relationship between pre-transgression relational qualities and post-transgression relationship outcomes.

\section{Motives}

In order to understand how CI motives might affect relationship outcomes, it is first necessary to recognize all of the facets of each identified CI motive, as motives are often multidimensional and complex. 
Jealousy. Jealousy is the first CI motive identified by Spitzberg and Tafoya (2005). Jealousy is made up of the "cognitive, emotional, and behavioral complex of reactions to a perceived threat of losing a valued partner to a real or imagined rival" ( $\mathrm{p}$. 7). Furthermore, Spitzberg and Tafoya base their work on the conceptualizations of jealousy outlined by Pfeiffer and Wong (1989). According to these scholars, cognitive jealousy involves the imagined suspicions of a partner's infidelity, and these suspicions can be based on accurate or false assumptions of a relational threat. Next, emotional jealousy refers to the feelings of hurt when thinking about a partner committing infidelity. For example, if an individual has been cheated on in the past, s/he may harbor jealous emotions from this relationship even after they have moved on to other relationships. Lastly, behavioral jealousy refers to the actions a person engages in that reveal jealous feelings. Behavioral jealousy involves the detective and protective measures a person takes with imagined or real relationship rivals. This can involve questioning, probing, or checking up on a partner.

When Spitzberg and Tafoya (2005) explored these three facets of jealousy, approval of CI was weakly related to behavioral jealousy. Furthermore, approval of CI was found to be unrelated to cognitive or emotional jealousy, which included thinking about a partner with another person, or simply fearing that a partner was with someone else. Overall, jealousy was not found to be an acceptable or justifiable motive for committing CI.

Sociosexuality. Sociosexuality is a CI motive driven by a desire for sexual experimentation, a need for sexual excitement, overall boredom with the relationship and/or the relational partner, and/or lack of attention from the partner (Spitzberg \& 
Tafoya, 2005). Individuals who focus primarily on their sex drive often desire unrestricted sociosexuality, as they want to be with a number of different people at any given time.

Spitzberg and Tafoya (2005) conceptualize sociosexuality as three-dimensional, comprised of sexual self-esteem, sexual preoccupation, and sexual depression. In explaining these dimensions of sociosexuality, Spitzberg and Tafoya call on prior work by Snell and Papini (1989) related to sex drive. These authors explain that sexual selfesteem refers to an individual's confidence in their sexuality and sexual experiences. Next, sexual preoccupation is defined as the tendency to think about sex to an excessive degree. Finally, sexual depression refers to the despair and unhappiness an individual feels about his/her sex life and sexuality. In Spitzberg and Tafoya's (2005) study, sexual preoccupation alone was positively related to the approval of CI. Conversely, sexual selfesteem and sexual depression were not significantly related to approval or justification of CI.

Vengefulness. More simply referred to as revenge, vengefulness can be a way to restore relational equity after one partner violates key rules for appropriate relational behavior (Spitzberg \& Tafoya, 2005). Vengefulness involves retaliation, "getting back" at the relational partner for his/her violation, or retribution. It is usually sparked by anger toward a perceived wrong in a relationship, and "implies a readiness toward negative reciprocity as a norm of distributive justice" (Spitzberg \& Tafoya, 2005, p. 10). Revenge motives can send the transgressive partner a message that equity must be restored, and possibly that rewards must increase. 
Tafoya and Spitzberg (2007) write, "Infidelity may be used as a tactic to maintain, repair, or terminate an otherwise dissatisfying relationship" (p. 232). To this point, however, there is no available empirical research suggesting the ways in which CI motives are related to relational outcomes. Since CI motives are intended to send a partner a specific message, it is highly likely that these motives will affect relational outcomes (i.e., termination, continuation, forgiveness, or reparation), as a response is expected after the message is sent. Additionally, it is instructive to explore these possible outcomes in relation to the investment model, as they may be influenced by the presence of relational commitment and satisfaction prior to the act of CI.

\section{Relationship Outcomes}

Rusbult, Zembrodt, and Gunn (1982) used investment model variables to predict reactions to relationship decline. They identified four primary reactions to relationship dissatisfaction: exit, voice, loyalty, and neglect. First, the exit reaction refers to relationship termination, or "formally separating" (p. 1231). For married couples, exit can involve divorce; whereas for dating couples, exit can include a change in relationship status from dating/romantic to "just friends." Exit reactions generally result in relationship termination. Second, voice reactions involve compromise, discussion of problems, suggesting solutions, or attempts to change the relationship to make it better. Individuals who have a voice reaction usually want the relationship to work out, so these responses tend to result in relationship continuation.

Next, Rusbult et al. (1982) conceptualize loyalty as waiting and hoping for improvement of the relationship over a period of time. Although loyalty reactions are not necessarily active, like voice reactions, they still involve hope for the relationship to 
continue. Therefore, they tend to result in relationship continuation as well. Lastly, neglect reactions involve ignoring the partner, refusing to discuss problems, or simply "letting things fall apart" (p. 1231). Neglect reactions can involve treating the partner badly physically or emotionally, and can sometimes involve extra dyadic sexual activity with the partner that is being neglected. Therefore, neglect reactions often lead to relationship termination. Consequently, voice and loyalty reactions can be grouped together into relationship continuation outcomes, while neglect and exit responses can be combined into relationship termination outcomes. Furthermore, forgiveness and reparation, as explained earlier in this study, can also be considered continuation outcomes, as they have been linked to pro-relationship motivations (Finkel et al., 2002).

Four early empirical studies by Rusbult et al. (1982) revealed associations among the predictors of satisfaction, investment, alternatives, and commitment and the relational outcomes of exit, voice, loyalty, and neglect. Specifically, high satisfaction prior to relationship deterioration or a relational transgression led to more voice and loyalty reactions and fewer exit and neglect responses. Similarly, low investment prior to relationship dissatisfaction inspired more exit and neglect responses, and less voice and loyalty reactions. Lastly, it was found that the perception of high alternatives encourages exit responses to relationship dissatisfaction and decreases loyalty behavior. These findings are consistent with the investment model. Based on this research, in conjunction with the forgiveness and reparation literature discussed earlier, several predictions can be made about relationship outcomes with regards to each CI motive.

First, Rusbult et al. (1982) found a positive relationship between satisfaction and voice/loyalty responses and a negative relationship between satisfaction and exit/neglect 
responses. As suggested by the general tenets of the investment model, satisfaction predicts relationship commitment, and likely relationship continuation (Rusbult, 1980, 1983). Empirical studies have shown that satisfaction is a primary component of relationship commitment and continuation (Bassett, 2005; Emmers-Sommer, 2003; Jones et al., 2001; Nannini \& Meyers, 2000; Weiderman \& LaMar, 1998). Satisfaction and commitment have also been linked to forgiveness and reparation strategies (BrandauBrown \& Ragsdale, 2008; Finkel et al., 2002; Kachadourian et al., 2004), such that highly satisfied and committed individuals are more likely to engage in forgiveness and repair strategies in response to relational transgressions. Taken together, the findings from these bodies of research lead to the first hypotheses of this study:

H1a: Individuals' pre-transgression commitment and satisfaction levels will be positively related to loyalty, voice, forgiveness, and reparation responses after discovering a romantic partners' CI transgression.

H1b: Individuals' pre-transgression commitment and satisfaction levels will be negatively related to exit and neglect responses after discovering a romantic partners' CI transgression.

Although a relationship between pre-transgression relational qualities and posttransgression responses has been suggested by extant research (Katz, Kuffel, \& Brown, 2006; Rhatigan \& Axsom, 2006; Rhatigan \& Street, 2005), it is expected that the motives for the transgression itself may subsequently impact relational outcomes. More specifically, Spitzberg and Tafoya (2005) found that jealousy, sexual depression, and sexual self-esteem are less acceptable and justifiable motives for committing CI, while sexual preoccupation and vengefulness are more acceptable and justifiable motives for 
committing CI. Therefore, relationship outcomes should be related to the acceptability and justifiability of the CI motives, as individuals who find a motive warranted and legitimate may be more likely to respond in a manner that will help rather than hurt the relationship. Conversely, if an individual finds a CI motive unacceptable and unreasonable, it appears likely that they will attempt to terminate the relationship. Based on these findings, the following hypotheses are proposed:

H2a: Exit and neglect responses will be more likely than loyalty, voice, forgiveness, and reparation responses in the cases of CI motivated by jealousy, sexual depression, and sexual self-esteem.

$\mathrm{H} 2 \mathrm{~b}$ : Loyalty, voice, forgiveness, and reparation responses will be more likely than exit and neglect responses in the cases of CI motivated by sexual preoccupation and vengefulness.

As argued previously, although the relationship between pre-transgression commitment and satisfaction levels and post-transgression outcomes has been widely supported (Choice \& Lamke, 1990; Drigotas et al., 1999; Guerrero \& Bachman, 2008), this relationship may be moderated by the motive for the CI transgression that was committed. That is, while we would expect a positive relationship between pretransgression commitment and post-transgression relational repair, for example, that relationship may change if the infidelity transgression was motivated by jealousy on the part of the partner.

Furthermore, research shows a positive correlation between relationship dissatisfaction and jealousy (Bassett, 2005; Emmers-Sommer, 2003; Jones et al., 2001; Nannini \& Meyers, 2000; Weiderman \& LaMar, 1998). Therefore, if jealousy is 
positively related to dissatisfaction and negatively related to voice and/or loyalty responses, CI motivated by jealousy should result in more exit and/or neglect responses than loyalty and/or voice responses. Moreover, in the study conducted by Spitzberg and Tafoya (2005), jealousy was not an acceptable or justifiable CI motive. Therefore, jealousy as a CI motive should result in relationship termination as opposed to continuation outcomes, because the partner is unlikely to find the motive acceptable. Taken together, this evidence leads to the next hypotheses of this study:

H3a: The relationship between pre-transgression commitment and satisfaction and post-transgression relational outcomes will be moderated by the motive for committing CI, such that the commitment and satisfaction relationship to loyalty, voice, forgiveness, and reparation outcomes will be weakest in the case of CI motivated by jealousy.

H3b: The relationship between pre-transgression commitment and satisfaction and post-transgression relational outcomes will be moderated by the motive for committing CI, such that the commitment and satisfaction relationship to exit and neglect will be strongest in the case of CI motivated by jealousy.

Sociosexuality as a CI motive may also moderate the relationship between pretransgression commitment and satisfaction and post-transgression relational outcomes. In the study conducted by Spitzberg and Tafoya (2005), sexual self-esteem and sexual depression, two of the three main components of sociosexuality, were negatively related to the approval of CI. A closer examination of the results reveals that sexual preoccupation was the only component of sociosexuality that was positively related to the 
approval of CI. Furthermore, it is revealed that individuals who focus specifically on their sex drive often desire unrestricted sociosexuality, as they are interested in a number of potential partners. Several empirical studies add to this, showing that high alternatives decrease relationship commitment (Drigotas et al., 1999; Guerrero \& Bachman, 2008; McAlister, Pachana, \& Jackson, 2005), and it is reasonable to assume that individuals interested in a number of potential partners may desire high alternatives as well.

If sexual self-esteem and sexual depression are negatively related to the approval of CI, it is reasonable to assume that this lack of approval will result in more relationship termination responses than relationship continuation responses, as the partner may be less accepting and understanding of the motive. Furthermore, if sociosexuality is usually associated with high alternatives and decreased commitment, relationship commitment and continuation should be negatively affected. In contrast, sexual preoccupation was positively related to the approval of CI in Spitzberg and Tafoya's (2005) study. Therefore, it is expected that this component may be the only dimension of sociosexuality that could result in more relationship continuation responses than relationship termination responses. This reasoning leads to the following hypotheses:

H4a: The relationship between pre-transgression commitment and satisfaction and post-transgression relational outcomes will be moderated by the motive for committing CI, such that the commitment and satisfaction relationship to loyalty, voice, forgiveness, and reparation outcomes will be weakest in the case of a CI motivated by sexual self-esteem or by sexual depression. 
H4b: The relationship between pre-transgression commitment and satisfaction and post-transgression relational outcomes will be moderated by the motive for committing CI, such that the commitment and satisfaction relationship to exit and neglect will be strongest in the case of a CI motivated by sexual self-esteem or by sexual depression.

H4c: The relationship between pre-transgression commitment and satisfaction and post-transgression relational outcomes will be moderated by the motive for committing CI, such that the commitment and satisfaction relationship to loyalty, voice, forgiveness, and reparation outcomes will be strongest in the case of a CI motivated by sexual preoccupation.

H4d: The relationship between pre-transgression commitment and satisfaction and post-transgression relational outcomes will be moderated by the motive for committing CI, such that the commitment and satisfaction relationship to exit and neglect will be weakest in the case of a CI motivated by sexual preoccupation.

Vengefulness is the final CI motive that should moderate the relationship between pre-transgression commitment and satisfaction and post transgression relational outcomes. In the study conducted by Spitzberg and Tafoya (2005), vengefulness was found to be the most approved of and justified motive of the three identified CI motives. These authors explain that revenge can be a way to restore relational equity, as it is driven by one partner trying to get back at the other. It is also important to note that vengefulness is a CI motive that is initiated by something the other partner did. It can be viewed as an attempt to restore satisfaction and increase commitment. Therefore, if 
vengefulness is an attempt to restore the overall equity of a relationship, and it was the most approved of and justified CI motive in Spitzberg and Tafoya's study, this motive should result in relationship continuation as opposed to relationship termination. This reasoning leads to the next hypotheses of this study:

H5a: The relationship between pre-transgression commitment and satisfaction and post-transgression relational outcomes will be moderated by the motive for committing CI, such that the commitment and satisfaction relationship to loyalty, voice, forgiveness, and reparation outcomes will be strongest in the case of a CI motivated by vengefulness.

H5b: The relationship between pre-transgression commitment and satisfaction and post-transgression relational outcomes will be moderated by the motive for committing CI, such that the commitment and satisfaction relationship to exit and neglect will be weakest in the case of a CI motivated by vengefulness.

Lastly, Spitzberg and Tafoya's (2005) study exposed significant sex differences between men and women in their approval and justification of CI, with men exhibiting more approval of and considering all three CI motives more justifiable than women in all cases. This suggests that sex differences may play a role in relationship outcomes after CI is committed. These findings suggest the final hypothesis and research question of this study:

H6: Men will evaluate all CI motives as more acceptable and justifiable than women. 
RQ1: Do the ways in which CI motives impact relationship outcomes differ for men and women? 


\section{CHAPTER TWO}

\section{Method}

Data collection for this project proceeded in two stages: initial pilot testing to aid in scenario development (Pilot Study), which was followed by the test of hypotheses and the research question (Study One). The pilot study consisted of four different data collections, in which participants were asked to imagine that their relational partner committed the behaviors described in one of the scenarios. While the partner's general behavior (i.e., commission and admission of an infidelity) remained consistent across scenarios, the motive for committing the infidelity varied by scenario, thus constituting the experimental manipulation for Study One. The behaviors presented in each scenario described one of the five aforementioned CI motives, resulting in a total of five scenarios. Participants in each pilot test read either one or all of the five scenarios (depending on the round of pilot testing in question), which were created based upon the information provided in a pilot study conducted by Spitzberg and Tafoya (2005), as well as author brainstorming.

Scenarios were modified and improved upon after each round of pilot testing in order to increase the number of participants who were able to correctly identify the CI motive, as well as to ensure that the scenarios were as realistic as possible. The final round of pilot testing indicated that participants were accurately able to identify the CI motive from the scenario they read, and that they found all of the scenarios to be relatively believable. The final five scenarios are presented in Appendix A, and more information regarding each round of pilot testing is provided below. 


\section{Pilot Study}

Pilot test one $(N=54)$ consisted of 31 men and 23 women ranging in age from 18 to $23(M=20.44, S D=1.04)$. Twenty participants reported being in a romantic relationship, with a mean relational length of 13.60 months $(S D=13.74)$. Each individual was only exposed to one scenario/motivation in this initial pilot test. Nine participants received the jealousy scenario, $84 \%$ of which were able to correctly recognize this motive. Nine individuals received the revenge scenario, and $44 \%$ were able to identify this motive. Sixty-one percent of the 13 individuals who received the sexual self-esteem scenario were able to correctly classify this motive, and $36 \%$ of the 11 participants who received the sexual depression scenario were able to accurately identify the motive. Lastly, $58 \%$ of the 12 individuals who received sexual depression were able to correctly recognize this motive. Results of a one-way analysis of variance (ANOVA) revealed no significant differences among scenarios with regard to their realistic nature $(F(4,49)=$ $0.68, p=.61$ ), and all scenarios were evaluated as relatively credible. More specifically, results from a one-sample $t$-test revealed that the means associated with the realistic nature of all CI scenarios $(M=5.24, S D=1.60, t(53)=24.05, p<.001)$ were significantly above the midpoint of the 7-point scale, demonstrating that all scenarios were perceived as believable. As such, the scenarios were deemed to be sufficiently realistic, and no further modifications to the scenarios were undertaken with regard to realism.

Improvements were made to the scenarios, however, with regard to clarifying and emphasizing the motives for the infidelity transgressions by directly stating the motive and adding more description of each motive. The revised scenarios were tested again in 
pilot test two $(N=12)$, which consisted of 4 men and 8 women ranging in age from 19 to $29(M=21.53, S D=2.21)$. Five participants reported being in a romantic relationship, with a mean relational length of 11 months $(S D=4.32)$. Each participant read all five scenarios along with a short description of each of the five motives in this pilot test, and participants were then asked to choose the motive that corresponded with each scenario. Results revealed that $84 \%$ of individuals were able to correctly identify the jealousy motive, $100 \%$ were able to identify revenge, $67 \%$ correctly identified sexual self-esteem, $92 \%$ were able to correctly identify sexual preoccupation, and $75 \%$ were able to correctly identify sexual depression.

As pilot test two indicated that accurate motive recognition was still not satisfactory, attempts were again made to clarify and emphasize the CI motives within the scenarios. Specifically, the scenarios were revised so that the background information in all five scenarios (i.e., everything except the experimental manipulation itself) was reconstructed to be exactly the same (see Appendix A). This was done in order to establish consistency among the scenarios and so that the motive manipulation was highlighted. The revised scenarios were examined again in pilot test three $(N=11)$, which consisted of 5 men and 6 women ranging in age from 19 to $29(M=21.62, S D=$ 2.13). Five participants reported being in a romantic relationship with a mean relational length of 11 months $(S D=4.32)$. Again, each participant read all five scenarios along with a brief description of each of the five motives, and participants were asked to choose the motive that corresponded with each scenario. Results revealed that $100 \%$ of individuals were able to correctly identify the motives for jealousy, sexual depression, 
sexual self-esteem, and sexual preoccupation. Ninety percent of individuals were able to correctly identify vengefulness.

Given that pilot test three resulted in nearly $100 \%$ accurate identification of all CI motives based on readings of the scenarios, the motives were judged to be sufficiently clear to participants. One final pilot test was conducted using the scenarios from pilot test 3 in order to assess the realistic nature of the final, revised scenarios. Pilot test four $(N=$ 47) consisted of 26 men and 21 women ranging in age from 18 to 23 years $(M=20.60$, $S D=1.09)$. Sixteen participants reported being in a romantic relationship with a mean relational length of $13.88(S D=12.33)$. Results of a one-way ANOVA revealed no significant differences in realism among motives $(F(4,42)=0.71, p=.59)$, and all scenarios were evaluated as relatively believable. More specifically, results from a onesample $t$-test revealed that the means associated with realism for the various versions of the scenarios were significantly above the midpoint of the scale $(M=5.28, S D=1.53, t$ $(46)=23.67, p<.001)$. As such, the scenarios were deemed to be sufficiently realistic, and the test of hypotheses and the research question commenced.

\section{Study One}

Participants. Data were initially collected from 287 undergraduate students at a large Mid-Atlantic university. However, an initial examination of the data revealed that a small subset of the sample did not correctly identify the CI motive in the scenario they read. Given that this study specifically aimed to test the effects of CI motives on relationship outcomes, participants who were not able to accurately identify the motive were removed from further analysis. This resulted in a final sample of 215 participants (109 men, 105 women, and one participant who did not indicate sex). Forty-five of these 
participants were exposed to the jealousy scenario, 46 received the revenge scenario, 38 read the sexual preoccupation scenario, 46 received the sexual depression scenario, and 40 participants read the sexual self-esteem scenario.

A convenience sample was used to obtain participants enrolled in multiple sections of communication courses. All individuals were required to be in an exclusive sexually active/romantic relationship at the time of their participation in the study. The vast majority of participants $(70.2 \%)$ self-reported on their involvement in a serious dating relationship, followed by $19.5 \%$ in a casual dating relationship, while $3.7 \%$ were engaged, $1.9 \%$ were married, $1.9 \%$ were just friends, and $0.9 \%$ of participants reported other as their relational status. Relationship lengths ranged from one month to 168 months $(M=16.88, S D=18.29)$. Additionally, small subsets of the sample reported having cheated on their current partner $(17.7 \%)$ or having been cheated on by their current partner $(15.8 \%)$.

Participants ranged in age from 18 to 32 years $(M=20.82, S D=1.97)$. Ethnic makeup of the sample was 91.6\% Caucasian, 4.2\% African American, 1.4\% Hispanic, $0.9 \%$ Asian, and $1.9 \%$ other. The class rank of the participants consisted of $14.0 \%$ freshmen, $25.6 \%$ sophomores, $29.3 \%$ juniors, $24.2 \%$ seniors, and $7.0 \%$ other. Additionally, $99.1 \%$ of participants were heterosexual, $0.5 \%$ of participants were gay/lesbian, and $0.5 \%$ reported being bisexual. Participants received minimal extra credit or course credit, and the study was approved by the university's institutional review board. 


\section{Procedures and Instrumentation}

Participants were recruited through classroom announcements, where they were informed of criteria for study participation, as well as times, dates, and locations of data collection. Flyers were also given to interested students as reminders. Upon arrival for data collection, participants signed in (in order to receive class credit), and were given a cover letter and questionnaire to complete (see Appendix B). Individuals' rights as research participants and the general instructions for questionnaire completion were verbally stated, and participants were given the opportunity to ask questions about their participation. Five questionnaire versions were distributed at random by using a random number chart to order questionnaires. The questionnaires were identical with the exception of the scenario (again, five scenarios representing each of the five CI motives were used as the experimental manipulation; see Appendix A). When finished, participants were asked to place their questionnaire in a covered box to assure anonymity and confidentiality.

\section{Measures}

The questionnaires consisted of three sections. The first section assessed the participants' commitment and satisfaction levels prior to imagining that their relational partner committed CI. Following that, participants were asked to read a scenario representing one of the five CI motives, in which the participant was asked to envision that his/her partner committed an infidelity and confessed to that infidelity. Importantly, this confession (i.e., the experimental manipulation) included an explicit explanation that the partner cheated due to one of the five CI motivations. Immediately following the scenario, participants were asked to answer manipulation check questions regarding 
identification of the motive for the infidelity they read about, the acceptability/ justifiability of the motive for infidelity, and the realistic nature of the scenario in general. The questionnaire concluded with measurements of potential relational outcomes after discovering the partner's infidelity. All measures were assessed on 1-7 Likert scales, where larger values represent "more" of the phenomenon in question. Each of the measures (and the procedure) is described in more detail below.

Investment model scale. Participants' commitment and satisfaction prior to imagining that their partner committed CI was assessed using the commitment (e.g., "I want our relationship to last forever") and satisfaction (e.g., "Our relationship makes me very happy”) dimensions of Rusbult, Martz, and Agnew’s (1998) Investment Model Scale. Past research has yielded coefficient reliabilities ranging from 0.88 to 0.90 for the commitment dimension and 0.90 to 0.91 for the satisfaction dimension (Drigotas et al., 1999; Guerrero \& Bachman, 2008; Rhatigan \& Axsom, 2006). Similar reliability coefficients were achieved here for both the commitment scale ( 7 items; $\alpha=0.89, M=$ $5.65, S D=1.21)$ and the satisfaction scale (10 items; $\alpha=0.94, M=5.77, S D=0.97)$.

After this, participants were instructed to move on to section two of the questionnaire where they were exposed to the CI motive manipulation, a scenario that included the discovery of a partner's transgression due to one of the five aforementioned motives. As noted previously, participants were randomly assigned to a condition. After reading the scenario, participants were then asked to respond to manipulation check items.

Manipulation check items. A forced-choice manipulation check question immediately followed the scenarios, asking participants to identify the CI motive 
described in the scenario. A list of the five CI motives was provided from which the participants were to choose, and participants who were unable to identify the motive were removed from further analysis.

Following this, six additional manipulation check items assessed the extent to which participants found the CI motive to be generally acceptable and justifiable (i.e., tolerable, acceptable, warranted, reasonable, legitimate, and justifiable). An exploratory factor analysis for these items was conducted utilizing the criteria suggested by Comrey and Lee (1992). Explicitly, eigenvalues exceeded 1.0 for retained factors with primary factor loadings of 0.50 or greater and no secondary loadings greater than 0.30 . A onefactor solution was obtained for ratings of the acceptability and justifiability of the CI motive, with all items loading at 0.78 or higher. Therefore, acceptability and justifiability were collapsed into one scale for all remaining analyses ( $\alpha=0.93, M=1.98, S D=1.18)$.

One item was used to assess how realistic participants found the scenario, and one item asked if a similar situation had happened to the participant. Although the majority of participants indicated that they had not experienced similar circumstances $(M=2.85, S D$ $=2.23)$, participants in this study did evaluate the scenarios as fairly realistic $(M=4.50$, $S D=2.04)$. More specifically, results from a one-way ANOVA revealed that perceptions of realism did not differ significantly across each of the CI motives $(F(4,210)=0.35, p$ $=.85)$. Furthermore, results from a one-sample $t$-test indicated that the means associated with the realistic nature of the CI scenarios $(M=4.56, S D=2.04, t(214)=32.72, p<$ .001) were significantly above the midpoint of the 7-point scale, demonstrating that all scenarios were perceived as relatively realistic. 
As it is difficult to induce relational threat via a hypothetical transgression using a scenario, and yet keep that scenario realistic in the minds of participants, assessments of the threatening and damaging nature of the scenarios were also employed. Specifically, one item was used to assess how relationally damaging participants found the scenario, and one item assessed the relational threat of the scenario. These data indicate that participants evaluated the scenarios as sufficiently relationally damaging $(M=5.83, S D=$ 1.68) and threatening $(M=5.93, S D=1.54)$. Following the scenario and manipulation check items, participants were instructed to move on to section three of the questionnaire. Section three assessed relational outcomes after discovering their partner's infidelity, which included continuation, termination, forgiveness, and reparation measures.

Continuation or termination measures. Relationship termination and continuation decisions were measured using Rusbult, Zembrodt, and Gunn's (1982) stay or leave measures. This scale consists of 20 items total and has exit (e.g., "I would end the relationship"), voice (e.g., "I would talk to my partner about what is bothering me"), loyalty (e.g., "When the problem emerged, I would wait, hoping things would get better") and neglect (e.g., "I would get angry and wouldn't talk at all") dimensions. Rusbult et al. reported coefficient reliabilities of 0.79 for the exit dimension, 0.80 for the voice dimension, 0.76 for the loyalty dimension, and 0.66 for the neglect dimension. Comparable reliability estimates were found here for the exit $(5$ items; $\alpha=0.87, M=$ 4.37, $S D=1.69$ ), voice ( 5 items; $\alpha=0.79, M=4.35, S D=1.45$ ), loyalty ( 5 items; $\alpha=$ $0.79, M=2.68, S D=1.29$ ), and neglect scales (5 items; $\alpha=0.65, M=3.13, S D=1.26$ ).

Forgiveness measures. Participants' forgiveness of a partner's CI was measured using Waldron and Kelley's (2005) 13-item Forgiveness Granting Scale as well as 
McCullough and Hoyt's (2002) 7-item Benevolence Scale. Waldron and Kelly's scale is a five-dimensional scale that measures communicative forgiveness by assessing individuals' explicit (e.g., "I would tell my partner that I forgive him/her”), conditional (e.g., "I would tell my partner that I would forgive him/her if the transgression never happened again"), nonverbal (e.g., "I would touch my partner in a way that communicated forgiveness"), minimizing (e.g., "I would tell my partner the transgression was no big deal"), and discussion (e.g., "I would discuss the offense with my partner") tendencies after a transgression takes place. Explicit forgiveness was measured with one global item as stated above. Waldron and Kelly reported coefficient reliabilities of 0.76 for conditional responses, 0.73 for the nonverbal dimension, 0.72 for forgiveness by minimizing items, and 0.76 for the forgiveness through discussion dimension. Reliability estimates for the present study are as follows: conditional forgiveness ( 3 items; $\alpha=0.80$, $M=3.47, S D=1.65$ ), nonverbal forgiveness (4 items; $\alpha=0.85, M=2.37, S D=1.41$ ), forgiveness by minimizing ( 3 items; $\alpha=0.64, M=1.76, S D=1.03$ ), and forgiveness through discussion ( 2 items; $\alpha=0.76, M=4.60, S D=1.94$ ).

Episodic forgiveness was measured using the Benevolence Scale (McCullough \& Hoyt, 2002). This scale asks participants the extent to which they feel goodwill toward the person who harmed them after a particular event, such as a relational transgression (e.g., "Even though his/her actions hurt me, I would still have goodwill for him/her"). Past research conducted with this scale has yielded a coefficient reliability of 0.90 (McCullough \& Hoyt, 2002). This 7-item scale yielded similar reliability estimates in the present study ( $\alpha=0.87, M=3.28, S D=1.43$ ). 
Reparation measure. Participants' reparation strategies were assessed using Emmers and Canary's (1996) repair scale. The original scale includes passive, active, interactive, and uncertainty acceptance items. For the purposes of this study, uncertainty acceptance items (e.g., "I decided to date others because I didn't care") were not included, as they are not reflective of our conceptualization of repair as the desire for the relationship to continue on some level. Passive (e.g., "I would give myself some time and space to think"), active (e.g., "I would give gifts to my partner"), and interactive (e.g., "I would spend time with my partner") items are more oriented toward general conceptualizations of repair, including the type of repair we are examining in this study. The scale consists of 25 items total for the three dimensions. Previous reliability coefficients of 0.81 (passive), 0.78 (active), 0.79 (interactive) have been reported (Emmers \& Canary, 1996). Passive repair consists of five items ( $\alpha=0.51, M=3.91$, $S D=0.97)$, active repair consists of six items $(\alpha=0.54, M=3.34, S D=0.96)$, and interactive repair consists of 14 items $(\alpha=0.89, M=3.69, S D=1.31)$. Given the extremely low reliability of the passive and active repair dimensions, these scales were deemed inappropriate for use in further analysis. 


\section{CHAPTER THREE}

Results

\section{Study One}

The first hypothesis (H1a) stated that higher pre-transgression commitment and satisfaction levels will be positively related to individuals' loyalty, voice, forgiveness, and reparation responses after discovering their partners' CI transgression. Results of a Pearson Correlation revealed that pre-transgression commitment is positively related to voice $(r=0.16, p=.02)$, indicating that committed individuals use voice responses after $\mathrm{CI}$ is revealed. No significant relationships were found between pre-transgression commitment or satisfaction and individuals' loyalty, forgiveness, and interactive repair responses. Thus, hypothesis 1a was only partially supported. See Table 1 for more detailed statistical information.

Hypothesis $1 \mathrm{~b}$ predicted that pre-transgression commitment and satisfaction levels will be negatively related to exit and neglect responses after discovering a partners' CI transgression. Results of a Pearson Correlation revealed that commitment is inversely related to neglect $(r=-0.17, p=.01)$, indicating that committed individuals do not use neglect responses after CI is revealed. Additionally, results of a Pearson Correlation indicated that pre-transgression satisfaction is inversely related to neglect responses $(r=-$ $0.14, p=.04)$, indicating that satisfied individuals do not use neglect responses after $\mathrm{CI}$ is revealed. No significant relationships were found between pre-transgression commitment or satisfaction and exit responses. Pearson Correlations also revealed that commitment $(r$ $=-0.18, p=.01)$ and satisfaction $(r=-0.16, p=.02)$ are negatively related to forgiveness by minimizing the transgression. Again, this hypothesis only received partial support. 
The second hypothesis (2a) stated that exit and neglect responses will be more likely than loyalty, voice, forgiveness, and reparation responses in the cases of CI motivated by jealousy, sexual depression, and sexual self-esteem. Additionally, hypothesis $2 \mathrm{~b}$ predicted that loyalty, voice, forgiveness, and reparation responses will be more likely than exit and neglect responses in the cases of CI motivated by sexual preoccupation and vengefulness. These hypotheses were tested using a multivariate analysis of variance (MANOVA), with the CI motive as the independent variable (with 5 levels representing each of the motives) and the relationship outcomes as the dependent variables. Results from this MANOVA did not support the hypothesis, and no significant relationships were found (see Table 2).

Hypotheses 3 through 5 posited moderating relationships among the independent variables (i.e., satisfaction and commitment) and the dependent variables (i.e., exit, voice, loyalty, neglect, forgiveness, and reparation). More specifically, it was proposed that the motive for committing CI would moderate the relationships between the independent variables and the dependent variables. As such, these hypotheses were tested via hierarchical regressions. First, CI motives (a nominal variable) was dummy-coded to allow for use in regression analyses. The moderating relationships were then tested by entering the independent variable (i.e., commitment or satisfaction) in the first step of the model, the moderating variable (i.e., CI motives, dummy-coded) on the second step, and the interaction term (i.e., the independent variable times the moderating variable) on the third step. The dependent variables changed based on the relationship under scrutiny. Hypothesis 3 a predicted that the relationship between pre-transgression commitment and satisfaction and post-transgression relational outcomes will be 
moderated by the motive for committing CI, such that the commitment and satisfaction relationship to loyalty, voice, forgiveness, and reparation outcomes will be weakest in the case of CI motivated by jealousy. Additionally, hypothesis $3 \mathrm{~b}$ predicted that the relationship between pre-transgression commitment and satisfaction and posttransgression relational outcomes will be moderated by the motive for committing CI, such that the commitment and satisfaction relationship to exit and neglect will be strongest in the case of CI motivated by jealousy. Results did not support the proposed hypotheses, as the interaction term was not statistically significant in any of the analyses. See tables three through seven for more detailed statistical analyses.

Hypothesis 4a stated that the relationship between pre-transgression commitment and satisfaction and post-transgression relational outcomes will be moderated by the motive for committing CI, such that the commitment and satisfaction relationship to loyalty, voice, forgiveness, and reparation outcomes will be weakest in the case of a CI motivated by sexual self-esteem or by sexual depression. In addition, Hypothesis $4 \mathrm{~b}$ predicted that the relationship between pre-transgression commitment and satisfaction and post-transgression relational outcomes will be moderated by the motive for committing CI, such that the commitment and satisfaction relationship to exit and neglect will be strongest in the case of a CI motivated by sexual self-esteem or by sexual depression. Results of hierarchical regressions did not support the proposed hypotheses. Tables three through seven display more information about the statistical analyses. Hypothesis $4 \mathrm{c}$ stated that the relationship between pre-transgression commitment and satisfaction and post-transgression relational outcomes will be moderated by the motive for committing $\mathrm{CI}$, such that the commitment and satisfaction relationship to 
loyalty, voice, forgiveness, and reparation outcomes will be strongest in the case of a CI motivated by sexual preoccupation. Likewise, hypothesis $4 \mathrm{~d}$ predicted that the relationship between pre-transgression commitment and satisfaction and posttransgression relational outcomes will be moderated by the motive for committing CI, such that the commitment and satisfaction relationship to exit and neglect will be weakest in the case of a CI motivated by sexual preoccupation. Results of hierarchical regressions did not support either of the proposed hypotheses. Tables three through seven provide more details on these hypotheses.

Hypothesis 5a stated that the relationship between pre-transgression commitment and satisfaction and post-transgression relational outcomes will be moderated by the motive for committing CI, such that the commitment and satisfaction relationship to loyalty, voice, forgiveness, and reparation outcomes will be strongest in the case of a CI motivated by vengefulness. Furthermore, Hypothesis $5 \mathrm{~b}$ predicted that the relationship between pre-transgression commitment and satisfaction and post-transgression relational outcomes will be moderated by the motive for committing CI, such that the commitment and satisfaction relationship to exit and neglect will be weakest in the case of a CI motivated by vengefulness. Again, results of hierarchical regressions did not support the proposed hypotheses. Refer to tables three through seven for more detailed statistical analyses.

Hypothesis 6 stated that men will rate all of the CI motives as more acceptable and justifiable than women. (Recall that factor analyses indicated that acceptability and justifiability constitute only one dimension; thus, the two were collapsed into one dependent variable for analyses.) Results of an independent samples $t$-test with motives 
as the independent variable and acceptability/justifiability as the dependent variable revealed that men $(M=2.06, S D=1.15)$ and women $(M=1.90, S D=1.22)$ did not differ in their acceptability/justifiability ratings for CI motives $(t(206)=1.02, p=.49)$. Given the low means, it appears that both sexes rated the motives as relatively unacceptable. Thus, this hypothesis was not supported.

Finally, the single research question of this study asked if men and women would differ in the ways in which CI motives influence their responses to CI transgressions. This research question was tested with a mixed-factor MANOVA, with sex (betweensubjects) and CI motive (within-subjects) as the independent variables and relationship continuation/termination, forgiveness, and interactive repair responses as the dependent variables. Results from the MANOVA revealed a statistically significant main effect for $\operatorname{sex}(F(1,184)=2.55, p=.01)$. Follow-up tests of these between-subjects effects revealed statistically significant differences in the ways that men and women use exit ( $F$ $\left.(1,184)=4.60, \mathrm{p}=.03 ; M_{\mathrm{men}}=4.59, S D_{\mathrm{men}}=1.65 ; M_{\text {women }}=4.14, S D_{\text {women }}=1.70\right)$, voice $\left(F(1,184)=9.77, p=.01 ; M_{\mathrm{men}}=4.03, S D_{\mathrm{men}}=1.43 ; M_{\text {women }}=4.69, S D_{\text {women }}=1.41\right)$, and neglect $\left(F(1,184)=4.71, p=.03 ; M_{\mathrm{men}}=3.34, S D_{\mathrm{men}}=1.28 ; M_{\mathrm{women}}=2.92\right.$, $\left.S D_{\text {women }}=1.21\right)$. That is, men reported reacting to the discovery of a partner's CI with more exit and neglect responses and less voice responses than women. No statistically significant main effects for CI motives $(F(4,184)=1.15, p=.23)$ were revealed, nor were any statistically significant interaction effects between sex and CI motives found with regard to the dependent variables $(F(4,184)=0.82, p=.81)$. 


\section{CHAPTER FOUR}

\section{Discussion}

The primary purpose of this study was to examine the effects of CI motives on relationship outcomes. More specifically, this investigation explored how the motives of jealousy, vengefulness, sexual depression, sexual self-esteem, and sexual preoccupation effect forgiveness, reparation, exit, voice, loyalty, and neglect responses after a relational partner's CI transgression is revealed. In addition, the relationship of pre-transgression commitment and satisfaction to post-transgression relational outcomes such as exit, voice, loyalty, neglect, and forgiveness were investigated. Finally, acceptability/justifiability ratings of the CI motives were evaluated for men and women, and sex differences were analyzed with regard to the ways in which the CI motives influence post-transgression relational responses from both sexes.

\section{Summary of Findings}

Results revealed that pre-transgression commitment and satisfaction are negatively related to post-transgression forgiveness by minimizing, suggesting that satisfied and committed individuals generally do not downplay the severity of a partner's infidelity as a forgiveness mechanism. Results also indicated that pre-transgression commitment is positively related to post-transgression voice responses and negatively related to post-transgression neglect responses, while pre-transgression satisfaction is negatively related to post-transgression neglect responses. These findings indicate that more committed and satisfied individuals desire relationship continuation after learning of a partner's transgression, and are likely to openly discuss the infidelity with their partner as a means to affect relationship maintenance. Contrary to the proposed 
relationships, however, the motive for infidelity commission did not influence the relationship between pre-transgression commitment and satisfaction and posttransgression relational outcomes. Additionally, while there were no significant interaction effects between the CI motives and sex, significant differences were found in the post-transgression relational responses of men and women. That is, men reported reacting to the discovery of a partner's $\mathrm{CI}$ with more exit and neglect responses and less voice responses than women. Finally, both sexes rated all CI motives as relatively unacceptable.

\section{Study Implications}

Based upon the large body of literature supporting the relationships among the investment model constructs and relational outcomes (e.g., Choice \& Lamke, 1990; Drigotas et al., 1999; Guerrero \& Bachman, 2008; Katz, Kuffel, \& Brown, 2006; Rhatigan \& Axsom, 2006; Rhatigan \& Street, 2005), it was expected that commitment and satisfaction would influence all relational outcomes in this investigation. Instead, commitment and satisfaction were only significantly related to voice, neglect, and forgiveness by minimizing the transgression. Although unanticipated, alternative bodies of extant research may provide plausible reasons for these findings.

First, approach-avoidance commitment research conducted by Frank and Brandstatter (2002) may account for some of the unexpected results of this study. Approach commitment refers to feelings of attachment, identity, and general happiness with a relationship, while avoidance commitment refers to the investments, energy, time, and loss that would result if the relationship were to end. In other words, approach commitment entails all that would be gained by relationship continuation, whereas 
avoidance commitment involves all that would be lost by the termination of a relationship. In examining whether approach and avoidance commitment are related to relationship quality, Frank and Brandstatter (2002) found that approach commitment (i.e., positive incentives) is positively correlated with relationship satisfaction, while avoidance commitment is positively correlated with investments. These findings suggest that investments can sometimes be perceived as a cause of relationship dissatisfaction, as they represent effortful inputs to a relationship that would then be lost if the relationship were to terminate. In other words, individuals may invest time, physical/emotional energy, and money (among other things) in order to maintain a relationship, but may not necessarily be happy doing so. Therefore, although investments have been shown to work to increase relational commitment (as suggested by the investment model; Rusbult, 1983), they may instead operate in a different manner. Rather than directly influencing commitment, investments may serve to decrease relational satisfaction, depending on how an individual perceives the costs of the investments that $\mathrm{s} / \mathrm{he}$ is putting into a relationship.

More generally, these findings also support the notion that different types of commitment may exist. For example, some scholars have conceptualized commitment as a tri-partite construct, including personal, moral, and structural commitment (Johnson, 1973, 1982, 1999). Although Rusbult $(1980,1983)$ conceptualizes commitment as an additive function of relational alternatives, investments, and satisfaction, Frank and Brandstatter (2002) suggest that an individual can be highly committed to a relationship because s/he perceives positive incentives (e.g., components of satisfaction such as happiness and love) to be high, or because s/he perceives costs (e.g., components of investments such as time and money) to be high. Importantly, however, Frank and 
Brandstatter suggest that both of these aspects of commitment do not necessarily coexist, in contrast to Rusbult et al.'s (1983) conceptualization of commitment in which investments combined with satisfaction (and relational alternatives) predict commitment. Perhaps a key consideration, then, is whether an individual perceives investments to be positive or negative. If investments are high and an individual perceives them positively (i.e., necessary for happiness, love, and identity sharing), then perhaps s/he will feel more committed to and satisfied with the relationship. Conversely, if investments are high and an individual perceives them to be negative and costly (i.e., a strain on their personal well-being/happiness), perhaps s/he will still be committed to the relationship but will also be unsatisfied with that relationship.

This line of reasoning leads to a plausible explanation why commitment and satisfaction were not related to all relational responses as expected in this study. That is, individuals may be committed to relationships by different means. When faced with infidelity, one of the most severe relational transgressions (Metts, 1994), commitment type - not just commitment itself - may be the deciding factor in continuation or termination. It is not unreasonable to posit that committed individuals who perceive investments positively and are driven by positive incentives may be more likely to engage in different relational responses after a transgression occurs than committed individuals who perceive investments negatively. For example, an individual high in commitment due to positive incentives may be more likely to engage in forgiveness though discussion, voice, loyalty, or interactive repair because s/he believes that there is more to be gained by staying in the relationship, and these constitute more pro-social responses to a transgression. Conversely, a committed individual who perceives relational 
investments to be costly and unrewarding may display more withdrawal responses to a transgression (e.g., exit and neglect), as there is less to be gained by remaining in the relationship.

Although the investment model has demonstrated its heuristic value in numerous studies (Choice \& Lamke, 1990; Drigotas et al., 1999; Guerrero \& Bachman, 2008; Katz, Kuffel, \& Brown, 2006; Rhatigan \& Axsom, 2006; Rhatigan \& Street, 2005), perhaps the responses to CI transgressions in this study would have been more accurately predicted if commitment were assessed in terms of approach and avoidance. Future research should examine not just commitment itself, but the effects of different types of commitment on relational responses. This knowledge may allow scholars to better understand the utility of measuring commitment based on content (i.e., positive incentives or negative incentives) or as an additive function of investments, alternatives, and satisfaction as suggested by the investment model.

In addition to the unexpected findings regarding the relationships of commitment and satisfaction to relational outcomes, extant research regarding CI and CI motives led to the postulation that the motive for the commission of CI - not necessarily the act of infidelity itself - would influence post-transgression relationship outcomes. However, data from this study suggest that CI motives do not affect relationship outcomes in the manner initially expected. In other words, the motive for committing CI in a relationship does not seem to matter with regard to how the transgression is dealt with post-discovery. Instead, what seems to matter is that CI was committed at all - not why it was committed. Although these results were unexpected based on the limited research that is currently 
available regarding CI transgressions, there are plausible reasons why these results were obtained.

A primary reason why CI motives do not affect relationship outcomes may be explained by Vangelisti and Young's (2000) work on hurtful messages. These researchers found that when individuals perceive that they are hurt by someone, they are likely to engage in relational distancing "regardless of the quality of their relationship with the person who hurt them and regardless of whether they felt they were hurt intentionally" (p. 418). This suggests that a hurtful message is hurtful regardless of current relationship quality or the intent of the source of the message. Perhaps these findings can be applied to the messages that are delivered to a partner when revealing CI. According to Tafoya and Spitzberg (2007), CI differs from other types of infidelity because it is specifically used to send a partner a message. Regardless of whether this message is intended to communicate jealousy, vengefulness, sexual depression, sexual self-esteem, or sexual preoccupation, learning from your partner that $\mathrm{s} /$ he committed infidelity is ultimately still a hurtful message. Relationship qualities such as commitment and satisfaction may become less salient, at least temporarily, if the receiver perceives the message to be hurtful and intentional. Framed by Vangelisti and Young's findings, all of the CI motivations may result in some type of relational distancing response, and the hurtful message may outweigh the maintenance power of relational commitment and satisfaction.

Furthermore, Vangelisti and Young (2000) found that hurtful messages that are sent for self-centered or trait-oriented (e.g., general, lasting tendencies to respond in certain ways, such as being selfish or inconsiderate) reasons often result in relational 
distancing. Applying these findings to the current study, recall that sexual preoccupation is the tendency to want and think about sex to an excessive degree, while vengefulness is a desire to get back at a partner for a perceived wrongdoing. Both of these CI motives may arguably fall under Vangelisti and Young's conceptualization of self-centered hurtful messages. Additionally, sexual-depression and sexual self-esteem may be examples of trait-oriented reasons to deliver a hurtful message, as depression and negative sexual self-esteem may be a manifestation of an individual's predispositions to behave in particular ways. These findings lead to the conclusion that the CI motivations may result in relational distancing and more termination responses than continuation responses. Future research should examine in more detail how CI motives are perceived by receivers, including whether they are evaluated as trait-oriented, self-centered, or relationship-centered motivations.

Facework and identity literature provide an additional possible explanation for the unanticipated findings of this investigation. In a study conducted by Wilson, Kunkel, Robson, Oufowote, and Soliz (2009), participants responded to a hypothetical situation by indicating what they would say to their romantic partner based on the information they were presented with in the hypothetical situation. These situations included initiating, intensifying, or disengaging from a romantic relationship in order to redefine the primary goals of the relationship. Participants also rated the extent to which they found the situation to be threatening to both parties' face. Responses were then coded for negative and positive politeness strategies. The researchers found that participants who crafted disengagement messages perceived the highest overall face threat to both relational 
partners and employed fewer politeness strategies (e.g., apologizing or soliciting input) in their attempts to terminate the hypothetical relationship.

It should be noted that the hypothetical termination scenario that participants were asked to imagine when formulating their responses did not include instances where the partner was clearly at fault for the deterioration of the relationship. In other words, participants were not asked to describe how they would terminate a relationship when their partner's bad behavior (as the result of an infidelity, for example) was the cause of the break-up. Instead, participants were asked to formulate a disengagement response simply because they were bored and no longer interested in the relationship. Therefore, if politeness was not used to save face when responding to a scenario wherein the partner had not violated any major relational rules, it is expected that politeness would certainly not be used when the partner admits to a transgression as serious as infidelity. Viewed in this light, it seems unlikely that continuation or other pro-social responses would result after an individual overtly threatens his/her romantic partner's face by confessing to an infidelity and claiming to have a justified motive for doing so, as was the case in the scenarios used in the present study.

Furthermore, an individual may engage in more termination responses as a means to possibly save his/her own face and re-establish personal identity after receiving this type of "threat" from a partner (Guerrero, Andersen, \& Afifi, 2001). Perhaps the importance of saving face, at least in imagined interactions such as those that were used in this study, overrides the influence of pre-transgression commitment and satisfaction in a relationship. Future research could verify or nullify this postulation by examining the 
role of commitment and satisfaction in face threatening situations within a romantic relationship, particularly after the $\mathrm{CI}$ is revealed.

\section{Limitations}

The findings of this study should be interpreted with an understanding of the limitations that were present. Methodologically, two scale reliabilities were deemed insufficient for hypotheses testing due to low alphas (i.e., passive and active repair). Thus, we were unable to assess these post-transgression outcomes. In addition, the reliability estimates for the post-transgression outcomes of neglect and forgiveness by minimizing were only marginally acceptable (i.e., 0.65 and 0.64 , respectively). Thus, the observed correlations involving these dependent variables were attenuated by the weak measures, and not as robust as they might have been using more reliable assessments (Furr \& Bacharach, 2008).

In addition, the use of a homogeneous, volunteer, purposive sample may limit the generalizability of the results (see Rosenthal, 1965). More specifically, it appears that this study drew participants who reported being highly satisfied with $(M=5.77, S D=0.97)$ and committed to $(M=5.65, S D=1.21)$ their relationships from the outset. This notably high level of satisfaction and commitment may have influenced numerous aspects of the study, from whether (and how) participants internalized the scenario manipulation to the accuracy with which they were able to envision how they would respond to such a scenario. In addition, the use of a college student sample from one university resulted in a homogeneous sample, which further limits generalizability of the findings outside of this particular population. 
The overall design of this study presents some limitations as well, given that this methodology only allows for the testing of correlational (rather than causal) claims. Moreover, the self-report nature of these data may contain biases that could threaten the study's validity, particularly given the sensitive and threatening nature of the experimental manipulation. In addition, and perhaps most problematic, all of the proposed relationships in this study were contingent upon the participant imagining that his/her partner committed CI due to a specific motive. However, responses that are elicited based upon imagining a hypothetical transgression scenario may result in data that are not entirely reflective of what an individual would do if the situation actually occurred (Bertrand \& Mullainathan, 2001). Unfortunately for "dark side" scholars interested in a deeper understanding of the nature and effects of infidelity in romantic relationships, this is one transgression that is particularly difficult to examine in situ.

\section{Conclusion}

In sum, the results of this investigation suggest that CI motives do not affect relationship outcomes. Nevertheless, Spitzberg and Tafoya's (2005) notion that infidelity may be committed specifically to send a partner a message is an area ripe for research. Exploring infidelity as a two-way dyadic process can help individuals to understand why infidelity is committed and work to prevent this type transgression before it actually occurs in a relationship. Instead of examining the motivations behind CI, future research could explore how CI is revealed to a partner and how communication of CI affects relational outcomes. In essence, this study illustrates the complex nature of romantic relationships and relational transgressions, providing a starting point for future research to further examine communicative infidelity. 


\section{References}

Allemand, M., Amberg, I., Zimprich, D., \& Fincham, F. D. (2007). The role of trait forgiveness and relationship satisfaction in episodic forgiveness. Journal of Social and Clinical Psychology, 26, 199-217.

Bassett, J. F. (2005). Sex differences in jealousy in response to a partner's imagined sexual or emotional infidelity with the same or different race other. North American Journal of Psychology, 7, 71-84.

Bertrand, M., \& Mullainathan, S. (2001). Do people mean what they say? Implications for subjective survey data. American Economic Review, 91, 67-72.

Boekhout, B. A., Hendrick, S. S., \& Hendrick, C. (2003). Exploring infidelity: Developing the relationship issues scale. Journal of Loss and Trauma, 8, 283-306.

Brandau-Brown, F. E., \& Ragsdale, J. D. (2008). Personal, moral, and structural commitment and the repair of marital relationships. Southern Communication Journal, 73, 68-83.

Choice, P. \& Lamke, L. K. (1990). Stay/leave decision-making processes in abusive dating relationships. Personal Relationships, 6, 351-367.

Comrey, A. L., \& Lee, H. B. (1992). A First Course in Factor Analysis (2 ${ }^{\text {nd }}$ Ed.). Hillsdale, NJ: Lawrence Erlbaum Associates Inc.

Davis L. E., \& Strube, M. J. (1993). An assessment of romantic commitment among black and white dating couples. Journal of Applied Social Psychology, 23, 212225.

Dindia, K., \& Baxter, L. A. (1987). Strategies for maintaining and repairing marital relationships. Journal of Social and Personal Relationships, 4, 143-158. 
Drigotas, S. M., Safstrom, C. A., \& Gentilia, T. (1999). An investment model prediction of dating infidelity. Journal of Personality and Social Psychology, 77, 509-524.

Dunleavy, K., Goodboy, A., Booth-Butterfield, M., Sidelinger, R., \& Banfield, S. (2007). Repairing hurtful messages in marital relationships. Paper presented at the convention of the International Communication Association, California.

Emmers, T. M., \& Canary, D. J. (1996). The effect of uncertainty reducing strategies on young couples' relational repair and intimacy. Communication Quarterly, 44, 166-182.

Emmers-Sommer, T. M. (2003). When partners falter: Repair after a transgression. In D. J. Canary \& M. Dainton (Eds.), Maintaining relationships through communication: Relational, contextual, and cultural variations (pp. 185-205). Mahwah, NJ: Lawrence Erlbaum Associates.

Fincham, F. D. (2000). The kiss of the porcupines: From attributing responsibility to forgiveness. Personal Relationships, 7, 1350-4126.

Finkel, E. J., Rusbult, C. E., Kumashiro, M., \& Hannon, P. A. (2002). Dealing with betrayal in close relationships: Does commitment promote forgiveness? Journal of Personality and Social Psychology, 82, 956-974.

Frank, E., \& Brandstatter, V. (2002). Approach versus avoidance: Different types of commitment in intimate relationships. Journal of Personality and Social Psychology, 82, 208-221.

Furr, R. M., \& Bacharach, V. R. (2008). Psychometrics: An introduction. Thousand Oaks, CA: Sage Publications Inc. 
Gordon, K. C., \& Baucom, D. H. (2003). Forgiveness and marriage: Preliminary support for a measure based on a model of recovery from a marital betrayal. American Journal of Family Therapy, 31, 179-199.

Guerrero, L. K., Andersen, P. A., \& Afifi, W. A. (2001). Close encounters: Communicating in relationships. Mountain View, CA: Mayfield Publishing Company.

Guerrero, L. K., \& Bachman, G. F. (2008). Communication following relational transgressions in dating relationships: An investment-model explanation. Southern Communication Journal, 73, 4-23.

Johnson, M. P. (1973). Commitment: A conceptual structure and empirical application. Sociological Quarterly, 14, 395-406.

Johnson, M. P. (1982). Social and cognitive features of the dissolution of commitment to relationships. In S. W. Duck (Ed.), Personal Relationships 4: Dissolving Personal Relationships (pp. 51-73). New York: Academic Press.

Johnson, M. P. (1999). Personal, moral, and structural commitment to relationships: Experiences of choice and constraint. In J. M. Adams \& W. H. Jones (Eds.), Handbook of interpersonal commitment and relationship stability (pp. 73-87). New York: Kluwer Academic/Plenum Publishers.

Jones, W. H., Moore, D. S., Schratter, A., \& Negel, L. A. (2001). Interpersonal transgressions and betrayals. In R. Kowalski (Ed.), Behaving Badly: Aversive behavior in interpersonal relationships (pp. 233-255). Washington, DC: American Psychological Association. 
Kachadourian, L. G., Fincham, F., \& Davila, J. (2004). The tendency to forgive in dating and married couples: The role of attachment and relationship satisfaction. Personal Relationships, 11, 373-393.

Katz, J., Kuffel, S. W., \& Brown, F. A. (2006). Leaving a sexually coercive dating partner: A prospective application of the investment model. Psychology of Women Quarterly, 30, 267-275.

Lin, Y. W., \& Rusbult, C. E. (1995). Commitment to dating relationships and cross-sex friendships in America and China. Journal of Social and Personal Relationships, $12,7-26$.

McAlister, A. R., Pachana, N., \& Jackson, C. J. (2005). Predictors of young dating adults' inclination to engage in extradyadic sexual activities: A multi-perspective study. British Journal of Psychology, 96, 331-350.

McCullough, M. E., \& Hoyt, W. T. (2002). Transgression-related motivational dispositions: Personality substrates of forgiveness and their links to the big five. Personality and Social Psychology Bulletin, 11, 1556-1573.

McCullough, M. E., Rachal, K., Sandage, S., Worthington, E., Brown, S., \& Hight, T. (1998). Interpersonal forgiving in close relationships: II. Theoretical elaboration and measurement. Journal of Personality and Social Psychology, 75, 1586-1603.

Metts, S. (1994). Relational transgressions. In W. R. Cupach \& B. H. Spitzberg (Eds.), The dark side of interpersonal communication (pp. 217-239). Hillsdale, NJ: Lawrence Erlbaum Associates.

Metts, S., \& Cupach, W. R. (2007). Responses to relational transgressions: Hurt, anger, and sometimes forgiveness. In B. H. Spitzberg \& W. R. Cupach (Eds.), The dark 
side of interpersonal communication ( $2^{\text {nd }}$ Ed.) (pp. 243-274). Mahwah, NJ:

Lawrence Erlbaum Associates.

Nannini, D. K., \& Meyers, L. S. (2000). Jealousy in sexual and emotional infidelity: An alternative to the evolutionary explanation. The Journal of Sex Research, 37, 117122.

Pfeiffer, S. M., \& Wong, P. T. P. (1989). Multidimensional jealousy. Journal of Social and Personal Relationships, 6, 181-196.

Roloff, M. E., Soule, K. P., \& Carey, C. M. (2001). Reasons for remaining in a relationship and responses to relational transgressions. Journal of Social and Personal Relationships, 18, 362-385.

Rosenthal, R. (1965). The volunteer subject. Human Relations, 18, 389-406.

Rhatigan, D. L., \& Axson, D. K. (2006). Using the investment model to understand battered women's commitment to abusive relationships. Journal of Family Violence, 21, 153-162.

Rhatigan, D. L., \& Street, A. E. (2005). The impact of intimate partner violence on decisions to leave dating relationships: A test of the investment model. Journal of Interpersonal Violence, 20, 1580-1597.

Rusbult, C. E. (1980). Commitment and satisfaction in romantic associations: A test of the investment model. Journal of Experimental Social Psychology, 16, 172-186.

Rusbult, C. E. (1983). A longitudinal test of the investment model: The development (and deterioration) of satisfaction and commitment in heterosexual involvements. Journal of Personality and Social Psychology, 45, 101-117. 
Rusbult, C. E., Bissonnette, V. L., Arriaga, X. B., \& Cox, C. L. (1998). Accommodation processes during the early years of marriage. In T. N. Bradbury (Ed.), The developmental course of marital dysfunction (pp. 74-113). New York, NY: Cambridge University Press.

Rusbult, C. E., Johnson, D. J., \& Morrow, G. D. (1986). Predicting satisfaction and commitment in adult romantic involvements: An assessment of the generalizability of the investment model. Social Psychology Quarterly, 49, 81-89.

Rusbult, C. E., Martz, J. M., \& Agnew, C. R. (1998). The Investment Model Scale: Measuring commitment level, satisfaction level, quality of alternatives, and investment size. Personal Relationships, 5, 357-391.

Rusbult, C. E., Zembrodt, I. M., \& Gunn, L. K. (1982). Exit, voice, loyalty, and neglect: Responses to dissatisfaction in romantic involvements. Journal of Personality and Social Psychology, 43, 1230-1242.

Snell, W. E., Jr., \& Papini, D. R. (1989). The sexuality scale: An instrument to measure sexual self-esteem, sexual depression, and sexual preoccupation. Journal of Sex Research, 26, 256-263.

Spitzberg, B. H., \& Chou, H. (2005, May). I did it on purpose: A model of strategic infidelity. Paper presented at the convention of the International Communication Association, New York.

Spitzberg, B. H., \& Tafoya, M. A. (2005, May). Further explanations in communicative infidelity: Jealousy, sociosexuality, and vengefulness. Paper presented at the convention of the International Communication Association, New York. 
Stafford, L., Dainton, M., \& Haas, S. (2000). Measuring routine and strategic relational maintenance: Scale revision, sex versus gender roles, and the prediction of relational characteristics. Communication Monographs, 67, 306-323.

Tafoya, M. A., \& Spitzberg, B. H. (2007). The dark side of infidelity: Its nature, prevalence, and communicative functions. In B. H. Spitzberg \& W. R. Cupach (Eds.), The dark side of interpersonal communication ( $2^{\text {nd }}$ ed.) (pp. 201-242). Mahwah, NJ: Lawrence Erlbaum Associates.

Tsang, J. A., McCullough, M. E., \& Fincham, F. D. (2006). The longitudinal association between forgiveness and relationship closeness and commitment. Journal of Social and Clinical Psychology, 25, 448-472.

Vangelisti, A. L., \& Young, L. Y. (2000). When words hurt: The effects of perceived intentionality on interpersonal relationships. Journal of Social and Personal Relationships, 17, 393-424.

Waldron, V. R., \& Kelley, D. L. (2005). Forgiving communication as a response to relational transgressions. Journal of Social and Personal Relationships, 22, 723742.

Weiderman, M. W., \& LaMar, L. (1998). “Not with him you don’t!”: Gender and emotional reactions to sexual infidelity during courtship. The Journal of Sex Research, 35, 288-297.

Wilson, S. R., Kunkel, A. D., Robson, S. J., Olufowote, J. O., \& Soliz, J. (2009). Identity implications of relationship (re)definition goals: An analysis of face threats and facework as young adults initiate, intensify, and disengage from romantic relationships. Journal of Social Psychology, 28, 32-61. 
Appendix A

\section{Jealousy Scenario}

You went out of town last weekend to visit friends in another city. Your relational partner stayed in town while you were away to spend time with his/her friends. When you return, your partner says, "We have to talk - I don't want you to hear this from someone else. While you were away, I got really drunk and I cheated on you." Your partner says that s/he is sorry for cheating on you, and that s/he wants to work things out with you.

You respond to your partner, saying "How could you?! You'd better have a really good reason for cheating on me! Why would you do this?"

Your partner explains that lately s/he has been feeling really jealous whenever you go out with friends, and worried that you may be unfaithful to him/her. Your partner says that $\mathrm{s} /$ he is afraid of losing you to someone else, and that s/he cannot stand the thought of you being with another person. Essentially, jealousy got the best of your partner, and your partner's affair was motivated by jealousy.

\section{Vengefulness Scenario}

You went out of town last weekend to visit friends in another city. Your relational partner stayed in town while you were away to spend time with his/her friends. When you return, your partner says, "We have to talk - I don't want you to hear this from someone else. While you were away, I got really drunk and I cheated on you." Your partner says that s/he is sorry for cheating on you, and that s/he wants to work things out with you.

You respond to your partner, saying "How could you? You'd better have a really good reason for cheating on me! Why would you do this?"

Your partner explains that lately s/he has noticed you flirting with other people a lot, and in fact, just two weeks ago s/he saw you making out with someone else at a party. Your partner says that $\mathrm{s} /$ he cheated on you as a way to get back at you for your bad behavior, in order to get revenge and to get even with you. Essentially, your partner's affair was motivated by revenge. 
Appendix A (Continued)

\section{Sociosexuality Scenario for Sexual Self-Esteem}

You went out of town last weekend to visit friends in another city. Your relational partner stayed in town while you were away to spend time with his/her friends. When you return, your partner says, "We have to talk - I don't want you to hear this from someone else. While you were away, I got really drunk and I cheated on you." Your partner says that s/he is sorry for cheating on you, and that s/he wants to work things out with you.

You respond to your partner, saying "How could you? You'd better have a really good reason for cheating on me! Why would you do this?"

Your partner explains that lately s/he has had no confidence in his/her sexual abilities because s/he doesn't feel like s/he is able to satisfy you in bed, and furthermore, you seem to find fault with his/her sexual performance. As a result, your partner has no selfesteem in the bedroom, and has been feeling bad about his/her sexuality and sexual abilities. Essentially, your partner's affair was motivated by a lack of sexual selfesteem.

\section{Sociosexuality Scenario for Sexual Preoccupation}

You went out of town last weekend to visit friends in another city. Your relational partner stayed in town while you were away to spend time with his/her friends. When you return, your partner says, "We have to talk - I don't want you to hear this from someone else. While you were away, I got really drunk and I cheated on you." Your partner says that $\mathrm{s} / \mathrm{he}$ is sorry for cheating on you, and that s/he wants to work things out with you.

You respond to your partner, saying "How could you? You'd better have a really good reason for cheating on me! Why would you do this?"

Your partner explains that s/he has become preoccupied with sex, and has been thinking about sex all the time. S/he points out that lately you have been too busy or not in the mood for sex, or just unwilling to have sex with him/her. So, your partner says this caused him/her to think about sex to an excessive degree - that s/he just can't stop thinking about it. Essentially, your partner's affair was motivated by sexual preoccupation. 
Appendix A (Continued)

Sociosexuality Scenario for Sexual Depression

You went out of town last weekend to visit friends in another city. Your relational partner stayed in town while you were away to spend time with his/her friends. When you return, your partner says, "We have to talk - I don't want you to hear this from someone else. While you were away, I got really drunk and I cheated on you." Your partner says that $\mathrm{s} / \mathrm{he}$ is sorry for cheating on you, and that s/he wants to work things out with you.

You respond to your partner, saying "How could you? You'd better have a really good reason for cheating on me! Why would you do this?"

Your partner explains that lately s/he has felt miserable about his/her sex life. Your partner says that s/he has been feeling so unhappy with your sex life because lately you haven't really wanted to have sex, and even when you do have sex it's not very satisfying for him/her. This caused your partner to become depressed about your sex life, and to have an affair. Essentially, your partner's affair was motivated by sexual depression. 
Appendix B

\section{WestVirginiaUniversity}

Department of Communication Studies

March 2009

Dear Participant:

You are being asked to participate in a study conducted by Principal Investigator Dr. Megan Dillow and Co-Investigator Colleen Malachowski, both in the Department of Communication Studies at West Virginia University. You must be 18 or older to participate in this study, and must be currently involved in an exclusive sexual relationship. This research is interested in your general feelings towards events in your relationship and your reaction to those events. This research study will fulfill requirements toward earning a Masters in Communication Theory and Research for the co-investigator. Completing the survey and submitting it indicates that you have agreed to participate in the study.

Do not put your name on this questionnaire to ensure anonymity. Please complete the survey independently and be sure to read the instructions carefully and answer honestly. There are no right or wrong answers. Participation in this study is voluntary. You may skip certain questions if you want and you may stop completing the survey at any time without fear of penalty. If you are a student your actual performance in this study or your refusal to participate or withdrawal from this study will in no way affect your class standing, grades, job status, or status in any athletic or other activity associated with West Virginia University. There are no known risks associated with participation in this study. However, in the event that you would like to further discuss issues brought up in this questionnaire, you can contact WVU's Carruth Center for Counseling and Psychological Service at (304) 293-4431. It should take approximately 25 minutes to complete.

If you would like more information regarding this research project, feel free to contact Principal Investigator Dr. Megan Dillow at 304-293-3905 or by email at mdillow@mix.wvu.edu. This study has been acknowledged by West Virginia University's Institutional Review Board. Thank you for your participation.

Sincerely,

Dr. Megan Dillow

Assistant Professor

Principal Investigator

mdillow@mix.wvu.edu
Colleen Malachowski

M.A. Student

Co-Investigator

cmalacho@mix.wvu.edu 


\section{Appendix B (Continued)}

Think of someone with whom you are currently involved in an exclusive sexual relationship.

Write his/her initials here

Please think of this person when filling out the rest of the survey.

\section{SECTION I}

Instructions: Please answer the following questions regarding your current exclusive sexual relationship. Respond to each statement by indicating how much you agree or disagree with it. Please circle the number that best represents your current romantic relationship using the following scale:

Strongly Disagree

12
Neutral/Mixed 3

4

5 Strongly Agree 6 7

1. etc.).

My partner fulfills my needs for intimacy (i.e., sharing thoughts, secrecy,

2. __ I want our relationship to last for a very long time.

3. ___ My partner fulfills my sexual needs (i.e., holding hands, kissing, etc.).

4. __ I want our relationship to last forever.

5. ___ My relationship is much better than others' relationships.

6. __ It is likely that I will date someone other than my partner within the next year.

7. ___ My partner fulfills my needs for emotional involvement (i.e., feeling emotionally attached, feeling good when another feels good, etc.).

8. ___ Our relationship does a good job of fulfilling my needs for intimacy,

9. __ I I am oriented toward the long-term future of my relationship (e.g., I imagine being with my partner several years from now).

10. ___ My partner fulfills my needs for security (i.e., trust, comfort, etc.).

11. ___ I feel very attached to our relationship and am very strongly linked to my partner.

12. ___ My partner fulfills my needs for companionship.

13. Our relationship makes me very happy.

14. I I would not feel very upset if our relationship were to end in the near future.

15. My relationship is close to ideal.

16. I _ I am committed to maintaining my relationship with my partner.

17. I I f feel/felt satisfied with our relationship. 
Appendix B (Continued)

\section{SECTION II}

Instructions: Affairs, infidelity, adultery, and extra-dyadic sexual involvement are all terms for "extra-relational sexual activities." For example, if you were to engage in seductive, flirtatious, romantic, or explicitly sexual behavior (e.g., kissing, petting, mutual masturbation, oral sex, anal sex, sexual intercourse, etc.) with another person(s) while in an exclusive sexual relationship with a partner, this would be an affair. An affair might be a one night stand or an ongoing series of sexual encounters. You do not need to be married to your partner in order to consider outside sexual activity an affair. People and cultures vary in the extent to which they view affairs as moral or immoral, acceptable or unacceptable, appropriate or inappropriate. Carefully consider the following scenario.

\section{Individual Scenarios are Inserted Here}

Instructions: Answer the following questions in relation to the scenario you just read.

1. After reading the scenario, what was your partner's motivation for committing the infidelity? (Please check one only):

jealousy

revenge

sexual preoccupation

sexual depression

sexual self-esteem

2. This situation, or a similar situation, has happened to me.

$\begin{array}{llllllllll}\text { Strongly Disagree } & 1 & 2 & 3 & 4 & 5 & 6 & 7 & \text { Strongly Agree }\end{array}$

3. How tolerable did you find your partner's motive for the affair to be?

$\begin{array}{llllllllll}\text { Not Tolerable At All } & 1 & 2 & 3 & 4 & 5 & 6 & 7 & \text { Very Tolerable }\end{array}$

4. How acceptable did you find your partner's motive for the affair to be?

$\begin{array}{lllllllll}\text { Not Acceptable At All } & 1 & 2 & 3 & 4 & 5 & 6 & 7 & \text { Very Acceptable }\end{array}$

5 . How warranted did you find your partner's motive for the affair to be?

$\begin{array}{lllllllll}\text { Not Warranted At All } & 1 & 2 & 3 & 4 & 5 & 6 & 7 & \text { Very Warranted }\end{array}$

6. How reasonable did you find your partner's motive for the affair to be?

$\begin{array}{lllllllll}\text { Not Reasonable At All } & 1 & 2 & 3 & 4 & 5 & 6 & 7 & \text { Very Reasonable }\end{array}$ 7. How legitimate did you find your partner's motive for the affair to be?

$\begin{array}{lllllllll}\text { Not Legitimate At All } & 1 & 2 & 3 & 4 & 5 & 6 & 7 & \text { Very Legitimate }\end{array}$

8. How realistic did you find this scenario to be?

$\begin{array}{llllllllll}\text { Not Realistic At All } & 1 & 2 & 3 & 4 & 5 & 6 & 7 & \text { Very Realistic }\end{array}$

9. How justifiable did you find your partner's motive for the affair to be?

$\begin{array}{lllllllll}\text { Not Justifiable At All } & 1 & 2 & 3 & 4 & 5 & 6 & 7 & \text { Very Justifiable }\end{array}$ 10. How damaging to your romantic relationship is your partner's infidelity?

$\begin{array}{lllllllll}\text { Not Very Damaging } & 1 & 2 & 3 & 4 & 5 & 6 & 7 & \text { Very Damaging }\end{array}$ 11. How threatening to your romantic relationship were your partner's actions when $\mathrm{s} / \mathrm{he}$ committed the infidelity?

$\begin{array}{lllllllll}\text { Not Very Threatening } & 1 & 2 & 3 & 4 & 5 & 6 & 7 & \text { Very Threatening }\end{array}$ 
Appendix B (Continued)

\section{SECTION III}

Instructions: Think about how you would respond to your partner's affair given his/her motive for engaging in the affair. Please circle the number that most honestly represents your feelings, keeping in mind that people chose to handle relational events in different ways. Use the following scale:

\begin{tabular}{ccccccc} 
Strongly Disagree & & Neutral/Mixed & \multicolumn{2}{c}{ Strongly Agree } \\
1 & 2 & 3 & 4 & 5 & 6 & 7 \\
\hline
\end{tabular}

1. __ I would talk to my partner about what is bothering me.

2. W When the problem emerged, I would wait, hoping things would get better.

3. I I I would end the relationship.

4. __ I guess I would just sort of let things fall apart.

5. I I I would suggest things that I thought would help us.

$6 . \quad$ I I would eventually forgive my partner, but not until later.

7. _ _ I would joke with my partner about it so they would know they were forgiven.

8. _ _ I would give my partner a look that communicated forgiveness.

9. __ I would tell my partner that I forgive him/her.

10. __ I w would spend time with my partner.

11. ___ I would give my partner time and space.

12. __ I would impose distance or avoid my partner.

13. I _ I would forgive my partner.

14. I I I would think about the circumstances that happened with my partner.

15. I _ I would stop the problematic behavior with my partner.

16. _ _ I would announce my commitment to my partner.

17. __ I would threaten to take action if my partner's behavior did not change.

18. __ I I would apologize to my partner.

19.___ I would write or call my partner.

20. I I would want us to bury the hatchet and move forward with our relationship.

21. ___ Despite what he/she did, I would want us to have a positive relationship again.

22. ___ I would give up my hurt and resentment.

23. ___ Although he/she hurt me, I would put the hurt aside so we could resume our relationship.

24. __ I would never consider ending the relationship, but would wait for it to improve.

25. I I I would try to figure out ways to get out of it.

26. ___ I would get angry and wouldn't talk at all.

27. __ I would ask my partner what was bothering him/her.

28. ___ I would tell my partner that I would forgive him/her only if things changed. 
Appendix B (Continued)

29. _ _ I would tell my partner not to worry about it.

30. I I I would initiate discussion about the offense with my partner.

31. _ I I would give my partner a hug.

32. __ I I would choose to be exclusive with my partner.

33. I _ I would try to get my partner to believe me.

34. _ _ I would have sex with my partner.

35. _ _ I would tell my partner the relationship was over.

36. I _ I would wait patiently.

37. W_ We would go our separate ways.

38. I I w would allow the relationship to die a slow death.

39. I I I would ask my partner what I was doing wrong.

40. _ _ I would wait to see what would happen.

41. _ I I would drop him/her like a hot potato.

42. _ _ I would offer my partner help or assistance.

43. __ I would slow things down with my partner (i.e., date casually or become friends).

44. ___ I would ask my partner to apologize.

45. I__ I would give myself some time and space to think.

46. __ I would tell my partner that I would forgive him/her if it never happened again.

47. ___ I would tell my partner it was no big deal.

48. ___ I would discuss the offense with my partner.

49. ___ The expression on my face would say "I forgive you."

50 . _ _ I would be patient with my partner.

51. I _ I would give gifts to my partner.

52. __ I w would consult others about my partner (i.e., family, friends, ex, etc.).

53. __ I would discuss my feelings with my partner.

54._I would watch television, and we probably wouldn't talk much.

55 . _ I I would try to fix things up.

56. _ _ I would hope that if I just hung in there, things would get better.

57. ___ I would tell my partner to leave.

58. ___ I would start treating my partner badly.

59.___ I would touch my partner in a way that communicated forgiveness.

60. I I I would initiate romantic dates or create a romantic atmosphere with my partner.

61. __ I would be comforting and supportive of my partner.

62. __ I would forgive him/her for what he/she did to me.

63. I I w would release me anger so I could work on restoring our relationship to health.

64. Even though his/her actions hurt me, I would still have goodwill for him/her.

65. ___ I would decide to do nothing about the event.

66. ____ I would listen to my partner's feelings. 
Appendix B (Continued)

\section{SECTION IV}

Instructions: Please provide the following information about yourself.

1. Sex (Please Circle One): Male Female

2. What year in school are you (Please check one)?

$\begin{array}{ll}1^{\text {st }} \text { Year } & \text { Senior } \\ \text { Sophomore } & \text { Other } \\ \text { Junior } & \text { N/A }\end{array}$

3. How old are you?

Years

4. What is your dominant racial background (Please check one)?

Asian

Black/African American

Native American
Hispanic

White/Caucasian

Other

5. Are you (Please check one)?

Heterosexual

Gay/Lesbian

Bisexual

Unsure

6. Is the sexual partner you have been reporting on today:

Male

or

Female?

(please circle one)

7. Are you and your partner (Please check one)?

Casually dating

Seriously dating

Engaged

Married
Just friends
Other

8. How long have you and your partner been involved in this exclusive sexual relationship?

Months

9. Have you ever cheated on the partner you've been reporting on today?

Yes

or No

10. Has the partner you've been reporting on today ever cheated on you?

$$
\text { Yes }
$$

or

No 
Table 1

Correlations among Pre-Transgression Commitment and Satisfaction, and Post-Transgression Loyalty, Voice, Forgiveness, and Reparation Responses

\begin{tabular}{|c|c|c|c|c|c|c|c|c|c|c|c|c|}
\hline & V1 & $\mathrm{V} 2$ & $\mathrm{~V} 3$ & V4 & V5 & V6 & V7 & V8 & V9 & V10 & V11 & V12 \\
\hline \multicolumn{13}{|l|}{ V1: Commitment } \\
\hline V2: Satisfaction & $.75^{* *}$ & & & & & & & & & & & \\
\hline V3: Loyalty & .07 & .02 & & & & & & & & & & \\
\hline V4: Voice & $.16^{*}$ & .13 & $.57 * *$ & & & & & & & & & \\
\hline V5: Neglect & $-.17 *$ & $-.14 *$ & -.02 & $-.30 * *$ & & & & & & & & \\
\hline V6: Exit & -.06 & .02 & $-.70 * *$ & $-.68 * *$ & $.39 * *$ & & & & & & & \\
\hline V7: Conditional Forgiveness & .02 & -.00 & $.64 * *$ & $.62 * *$ & $-.22 * *$ & $-.69 * *$ & & & & & & \\
\hline V8: Forgiveness by Minimizing & $-.18 *$ & $-.16^{*}$ & $.48 * *$ & $.21 * *$ & .05 & $-.38 * *$ & $.32 * *$ & & & & & \\
\hline V9: Nonverbal Forgiveness & -.02 & -.06 & $.66^{* *}$ & $.54 * *$ & $-.16^{*}$ & $-.68 * *$ & $.60 * *$ & $.65 * *$ & & & & \\
\hline V10: Episodic Forgiveness & .04 & .01 & $.70 * *$ & $.66^{* *}$ & $-.27 * *$ & $-.73 * *$ & $.77 * *$ & $.49 * *$ & $.75^{* *}$ & & & \\
\hline V11: Explicit Forgiveness & .01 & -.03 & $.48 * *$ & $.48 * *$ & $-.22 * *$ & $-.51 * *$ & $.54 * *$ & $.42 * *$ & $.68 * *$ & $.68 * *$ & & \\
\hline V12: Forgiveness by Discussion & .12 & .12 & $.20 * *$ & $.58 * *$ & $-.21 * *$ & $-.32 * *$ & $.36^{* *}$ & -.01 & $.28 * *$ & $.42 * *$ & $.34 * *$ & \\
\hline V13: Interactive Repair & .08 & .05 & $.71 * *$ & $.81 * *$ & $-.23 * *$ & $-.77 * *$ & $.78 * *$ & $.40 * *$ & $.75^{* *}$ & $.81 * *$ & $.58 * *$ & $.54 * *$ \\
\hline
\end{tabular}


Table 2

Multivariate Analysis of Variance Assessing the Relationships among CI Motives and Relational Responses

\begin{tabular}{lcc}
\hline Response & $F(d f)$ & $p$ \\
\hline Loyalty & $1.28(4,210)$ & .28 \\
Voice & $0.97(4,209)$ & .43 \\
Neglect & $0.57(4,209)$ & .68 \\
Exit & $1.33(4,210)$ & .26 \\
Conditional Forgiveness & $0.82(4,210)$ & .51 \\
Forgiveness by Minimizing & $1.56(4,209)$ & .41 \\
Nonverbal Forgiveness & $1.00(4,210)$ & .38 \\
Episodic Forgiveness & $1.06(4,207)$ & .66 \\
Explicit Forgiveness & $0.60(4,210)$ & .47 \\
Forgiveness by Discussion & $0.90(4,209)$ & .06 \\
Interactive Repair & $2.26(4,208)$ & \\
\hline$N o t e: *<.05 * * *<.01$ & & \\
& &
\end{tabular}

Note: $* p<.05, * * p<.01$ 
Table 3

Hierarchical Regression Testing the Moderating Impact of CI Motive on the Relationship between Pre-Transgression Commitment and Post-Transgression Voice Responses

\begin{tabular}{lccc}
\hline Moderating Variable & Beta & $t$ & $p$ \\
\hline Jealousy & 0.02 & 0.07 & .95 \\
Revenge & 0.13 & 0.40 & .70 \\
Sexual Self-Esteem & -0.16 & -0.48 & .63 \\
Sexual Depression & 0.42 & 1.24 & .22 \\
Sexual Preoccupation & -0.52 & -1.58 & .12 \\
\hline
\end{tabular}

Note: $* p<.05, * * p<.01$ 
Table 4

Hierarchical Regression Testing the Moderating Impact of CI Motive on the Relationship between Pre-Transgression Commitment and Post-Transgression Neglect Reponses

\begin{tabular}{lccc}
\hline Moderating Variable & Beta & $t$ & $p$ \\
\hline Jealousy & -0.28 & -0.87 & .38 \\
Revenge & 0.19 & 0.55 & .54 \\
Sexual Self-Esteem & -0.20 & -0.62 & .57 \\
Sexual Depression & 0.19 & 0.57 & .81 \\
Sexual Preoccupation & 0.08 & 0.25 & \\
\hline
\end{tabular}

Note: $* p<.05, * * p<.01$ 
Table 5

Hierarchical Regression Testing the Moderating Impact of CI Motive on the Relationship between Pre-Transgression Satisfaction and Post-Transgression Neglect Responses

\begin{tabular}{lccc}
\hline Moderating Variable & Beta & $t$ & $p$ \\
\hline Jealousy & -0.06 & -0.15 & .88 \\
Revenge & 0.10 & 0.21 & .84 \\
Sexual Self-Esteem & -0.06 & -0.15 & .88 \\
Sexual Depression & -0.09 & -0.18 & .86 \\
Sexual Preoccupation & 0.04 & 0.10 & .92 \\
\hline
\end{tabular}

Note: $* p<.05, * * p<.01$ 
Table 6

Hierarchical Regression Testing the Moderating Impact of CI Motive on the Relationship between Pre-Transgression Commitment and Post-Transgression Forgiveness by

Minimizing Responses

\begin{tabular}{lccc}
\hline Moderating Variable & Beta & $t$ & $p$ \\
\hline Jealousy & -0.48 & -1.50 & .14 \\
Revenge & 0.10 & 0.28 & .78 \\
Sexual Self-Esteem & 0.12 & 0.38 & .70 \\
Sexual Depression & 0.31 & 0.94 & .35 \\
Sexual Preoccupation & 0.04 & 0.11 & .92 \\
\hline
\end{tabular}

Note: $* p<.05, * * p<.01$ 
Table 7

Hierarchical Regression Testing the Moderating Impact of CI Motive on the Relationship between Pre-Transgression Satisfaction and Post-Transgression Forgiveness by

Minimizing Responses

\begin{tabular}{lccc}
\hline Moderating Variable & Beta & $t$ & $p$ \\
\hline Jealousy & -0.37 & -0.93 & .35 \\
Revenge & 0.45 & 1.04 & .30 \\
Sexual Self-Esteem & 0.20 & 0.54 & .61 \\
Sexual Depression & -0.25 & -0.52 & .97 \\
Sexual Preoccupation & 0.02 & 0.03 & \\
\hline
\end{tabular}

Note: $* p<.05, * * p<.01$ 


\title{
Colleen C. Malachowski
}

\author{
Email: cmalacho@mix.wvu.edu \\ 108 Armstrong Hall \\ P.O. Box 6293 \\ Morgantown, WV 26505
}

\section{Education}

Masters of Arts - West Virginia University - Morgantown, WV

Major: Communication Theory and Research

Date of Graduation: August 2009

GPA 3.8

Bachelor of Arts - Boston College - Chestnut Hill, MA

Major: Communication

Minor: History

GPA: 3.5

\section{Professional Skills and Accomplishments}

\section{Research/Quantitative Analysis/Qualitative Analysis Experience}

- Completed thesis examining communicative infidelity in romantic relationships

- Conducted 4 full research studies in the last academic year, which included survey creation, entering data, and analyzing results

- Conducted both quantitative and qualitative research

- Developed reliable surveys with appropriate questions for intended audiences

- Analyzed data using the SPSS software and statistics such as t-tests, regressions, and correlations

- Completed 36 course credits at the graduate level, including research methods

- Completed ethics and HIPAA training courses

\section{Communication Experience}

- Presented research at the 2009 Eastern Communication Association Convention, PA

- Guest lecturer in a college classroom with 300+ students on instructional communication

- Placed second in the Boston College Leonard Persuasive Speaking Contest, 2007/2008

\section{Employment History}

- Graduate Teaching Assistant, West Virginia University, Morgantown, WV, 2008-2009

- Undergraduate Teaching Assistant, Boston College, Chestnut Hill, MA, 2007-2008

- Work-Study Secretary, Boston College Communication Department, 2006-2008

- Advertising Intern, The Ad Club, Boston, MA, 2007

\section{Computer Skills}

- Proficient in SPSS, Microsoft Word, Excel, and PowerPoint 